\title{
节水减氮对土壤硝态氮分布和冬小麦水氮利用效率的影响
}

\author{
雒文鹤师祖姣王旭敏李 军 ${ }^{*}$ 王 瑞
}

西北农林科技大学农学院 / 农业部西北黄土高原作物生理生态与耕作重点实验室, 陕西杨凌 712100

摘 要: 针对当前关中平原冬小麦生产中氮肥投入过量、灌溉水资源不足的问题, 研究节水减氮栽培模式下冬小麦 籽粒产量、水氮利用及硝态氮淋失情况, 能为确定冬小麦节水减肥环保增效的生产模式提供理论依据。于 2017-2019 年在陕西杨凌开展冬小麦节水减氮田间栽培试验, 采用二因素裂区设计, 施氮量为主处理, 灌水量为副处理, 设施 氮量处理 N300 $\left(300 \mathrm{~kg} \mathrm{hm}^{-2}\right) 、 \mathrm{~N} 225\left(225 \mathrm{~kg} \mathrm{hm}^{-2}\right) 、 \mathrm{~N} 150\left(150 \mathrm{~kg} \mathrm{hm}^{-2}\right) 、 \mathrm{~N} 75\left(75 \mathrm{~kg} \mathrm{hm}^{-2}\right) 、 \mathrm{~N} 0$ (不施氮)和灌水量处 理 W2 (1200 $\left.\mathrm{m}^{3} \mathrm{hm}^{-2}\right) 、 \mathrm{~W} 1\left(600 \mathrm{~m}^{3} \mathrm{hm}^{-2}\right)$ 、W0 (0), 分析小麦产量、水氮利用效率及土壤硝态氮淋失情况。结果表明, 2017-2018 年和 2018-2019 年小麦季灌水处理较不灌水处理分别增产 $14.88 \%$ 15.01\%和 4.11 4.16 倍, 但处理间差 异不显著, 而越冬期灌水 $600 \mathrm{~m}^{3} \mathrm{hm}^{-2}$ 土壤硝态氮淋失风险显著降低。在越冬期灌水 $600 \mathrm{~m}^{3} \mathrm{hm}^{-2}$ 处理下, 2017-2018 年施氮量 $150 \mathrm{~kg} \mathrm{hm}^{-2}$ 处理产量最高, 2018-2019 年则是施氮量 $225 \mathrm{~kg} \mathrm{hm}^{-2}$ 处理产量最高, 但 2018-2019 年施氮量 $150 \mathrm{~kg} \mathrm{hm}^{-2}$ 处理在较高产量基础上获得较高的氮肥利用效率, 土壤硝态氮淋失量也较施氮量 $225 \mathrm{~kg} \mathrm{hm}^{-2}$ 处理 2 个年 度分别降低了 $15.87 \%$ 和 $10.20 \%$ 。因此, 施氮量 $150 \mathrm{~kg} \mathrm{hm}^{-2}$ 配合越冬期灌水 $600 \mathrm{~m}^{3} \mathrm{hm}^{-2}$, 能够在保障产量的基础上, 提高水氮利用效率，降低硝态氮淋失风险，实现关中平原冬小麦生产节水减肥环保增效的目标。

关键词: 冬小麦; 节水减氮; 产量; 水分利用效率; 氮肥利用效率; 硝态氮淋失量

\section{Effects of water saving and nitrogen reduction on soil nitrate nitrogen distribu- tion, water and nitrogen use efficiencies of winter wheat}

\author{
LUO Wen-He, SHI Zu-Jiao, WANG Xu-Min, LI Jun ${ }^{*}$, and WANG Rui \\ College of Agronomy, Northwest A\&F University / Key Laboratory of Crop Physiology and Tillage Science in Northwestern Loess Plateau, Ministry \\ of Agriculture, Yangling 712100, Shaanxi, China
}

\begin{abstract}
In order to solve the problems of excessive nitrogen input and irrigation water resources scarcity in current winter wheat production in Guanzhong Plain, winter wheat grain yield, water and nitrogen use efficiency, and nitrate nitrogen leaching were investigated to hopefully provide a theoretical basis for determining water-saving and nitrogen-reducing cultivation model. The two-factor split-plot field experiment (2017-2019) was conducted in Yangling, Shaanxi province, China, where the nitrogen application rates of N300 $\left(300 \mathrm{~kg} \mathrm{hm}^{-2}\right), \mathrm{N} 225\left(225 \mathrm{~kg} \mathrm{hm}^{-2}\right), \mathrm{N} 150\left(150 \mathrm{~kg} \mathrm{hm}^{-2}\right), \mathrm{N} 75\left(75 \mathrm{~kg} \mathrm{hm}^{-2}\right), \mathrm{N} 0\left(0 \mathrm{~kg} \mathrm{hm}{ }^{-2}\right.$, no nitrogen application) were assigned to the main plots, and the irrigation amount of W2 $\left(1200 \mathrm{~m}^{3} \mathrm{hm}^{-2}\right)$, W1 $\left.\left(600 \mathrm{~m}^{3} \mathrm{hm}\right)^{-2}\right)$, W0 $(0$, no irrigation) were assigned to the subplots. The amount of irrigation and nitrogen application had significant effects on wheat yield, water and nitrogen use efficiency, soil nitrate nitrogen content as well as its leaching loss. In the 2017-2018 and 2018-2019 wheat seasons, the irrigation treatments (W1 and W2) significantly increased the wheat yield by $14.88 \%-15.01 \%$ and $4.11-4.16$ times, respectively, but the difference between them was not significant, while the risk of soil nitrate nitrogen leaching under irrigation of $600 \mathrm{~m}^{3} \mathrm{hm}^{-2}$ in overwintering period was significantly reduced. Under the irrigation of $600 \mathrm{~m}^{3} \mathrm{hm}^{-2}$ in overwintering period, the yield was the highest in N150 treatment in 2017-2018, and in N225 treatment in 2018-2019, the N150 treatment had higher nitrogen use efficiency, and soil nitrate nitrogen leaching was also reduced by $15.87 \%$ and $10.20 \%$ compared with that of N225 treatment in 2017-2019. Therefore, N150 treatment (with nitrogen application rate of $150 \mathrm{~kg} \mathrm{hm}^{-2}$ ) combined with W1 treatment
\end{abstract}

本研究由国家科技支撑计划项目(2015BAD22B02)和国家自然科学基金项目(31801300)资助。

The study was supported by the National Science and Technology Support Program of China (2015BAD22B02) and the National Natural Science Foundation of China (31801300).

*通信作者(Corresponding author): 李军, E-mail: junli@nwsuaf.edu.cn

第一作者联系方式: E-mail: luowh09@foxmail.com

Received (收稿日期): 2019-10-06; Accepted (接受日期): 2020-01-15; Published online (网络出版日期): 2020-01-23.

URL: http://kns.cnki.net/kcms/detail/11.1809.S.20200123.1311.006.html 
(irrigated $600 \mathrm{~m}^{3} \mathrm{hm}^{-2}$ in overwintering period) can improve the water and nitrogen utilization efficiencies and reduce the risk of nitrate nitrogen leaching, realizing the water-saving and nitrogen reduction production of winter wheat in Guanzhong Plain.

Keywords: winter wheat; water saving and nitrogen reduction; grain yield; water use efficiency; nitrogen use efficiency; nitrate nitrogen leaching

施氮和灌水是作物增产的重要手段, 但我国农 业生产中却普遍存在肥料利用效率低和灌溉水资源 员乏的问题, 主要农作物对氮肥的利用率平均只有 $28 \% \sim 41 \%$ ，远低于世界 $40 \% \sim 60 \%$ 的平均利用率 ${ }^{[1-2]}$ 。 我国冬小麦推荐施氮量为 $150 \sim 250 \mathrm{~kg} \mathrm{hm}^{-2}[3]$, 而关 中平原实际生产中普遍存在施氮过量现象, 目前农 户麦田常规施氮量约为 $225 \mathrm{~kg} \mathrm{hm}^{-2[4-6]}$ 。过量氮肥投 入远超作物生长需求, 使作物增产效果、氮肥利用效 率降低, 造成氮肥资源浪费, 生产成本增高, 同时超 出作物吸收范围的氮素累积在土壤中, 易引起土壤 板结和环境污染等不良影响 ${ }^{[7-8]}$ 。陕西关中地区降雨 主要集中在每年的 7 月至 9 月, 冬小麦生育期降雨量 仅为全年的 $37 \%^{[9]}$, 降水不足且时空分布不均, 小麦 需水关键期水分不足, 补水灌溉是保证作物高产稳 产的重要措施。但关中平原属于水资源严重缺乏区, 普遍存在水资源短缺和灌溉方式不合理等问题 ${ }^{[10-11]}$, 大水大肥的小麦生产模式, 不仅降低了水肥利用率, 更加剧了水资源短缺问题 ${ }^{[2]}$ 。研究关中平原节水减氮 栽培条件下冬小麦产量、水氮利用效率以及硝态氮淋 失量, 有助于实施节本增效和绿色环保农业生产方 式。前人研究表明, 合理的水氮配置对小麦产量形成 和水氮利用都至关重要, 二者在一定范围内对产量 有明显正效应, 且二者耦合效应显著 ${ }^{[13-14]}$, 超过最佳 施氮量范围产量增加不显著甚至降低 ${ }^{[15-16]}$, 过量氮 肥不仅对作物增产无益, 还会降低氮肥利用率, 造成 资源浪费环境污染 ${ }^{[17-19]}$ 。水分不足会限制氮肥肥效发 挥, 水分过多则增加了氮肥淋溶风险 ${ }^{[20-22]}$, 过量施氮 与灌水已经导致大量氮素以硝态氮形式随水分淋溶 至作物根层之下的深层土壤, 并且硝态氮积累峰已 有逐年下移趋势 ${ }^{[23-25]}$ 。优化麦田氮肥管理, 提高氮素
利用率, 减少水资源浪费, 提高水分利用率, 发展高 效节水减肥生产, 是实现农业绿色发展, 保障粮食安 全和生态安全的重要举措, 尽管前人已经对施氮或 灌水与小麦产量、水肥利用效率和硝态氮积累关系进 行了探索研究, 但对水氮共同作用下的产量效应与 环境效应仍需进一步研究与探讨。本研究在关中平原 冬小麦高水高肥的生产基础上, 通过适当减少施氮 量和灌水量, 研究冬小麦对水氮吸收利用效率和土 壤硝态氮分布以及淋失情况, 在低环境成本和高水 氮利用效率条件下最大化小麦产量, 缓解生产中过 量施肥与水资源短缺的矛盾, 为关中平原节水减肥 条件下实现小麦高产稳产提供理论依据。

\section{1 材料与方法}

\section{1 试验地概况}

陕西省杨凌示范区西北农林科技大学曹新庄试 验农场 $\left(108^{\circ} 07^{\prime} \mathrm{E}, 34^{\circ} 20^{\prime} \mathrm{N}\right)$, 年均气温 $12.9^{\circ} \mathrm{C}$, 年均 降水量 $635.1 \mathrm{~mm}$, 无霜期 $211 \mathrm{~d}$, 属于大陆性季风暖 温带半湿润气候, 供试土壤为塿土, $0 \sim 30 \mathrm{~cm}$ 土壤质 地为壤质黏土, 30 100 cm 为粉沙质黏土, $100 \mathrm{~cm}$ 之 下为重壤土, 试验开始前土壤养分含量见表 1 。 0 $20 \mathrm{~cm} 、 20 \sim 40 \mathrm{~cm} 、 40 \sim 60 \mathrm{~cm}$ 土层土壤容重分别 为 $1.20 \mathrm{~g} \mathrm{~cm}^{-3} 、 1.38 \mathrm{~g} \mathrm{~cm}^{-3} 、 1.49 \mathrm{~g} \mathrm{~cm}^{-3}, 60 \mathrm{~cm}$ 以下 土层以 $1.49 \mathrm{~g} \mathrm{~cm}^{-3}$ 计算。该地区常年每月降雨量见 图 1, 试验期间, 2017 年 10 月至 2018 年 9 月全年降 雨量 $690.4 \mathrm{~mm}$, 小麦 2017 年 10 月 19 日播种, 2018 年 6 月 5 日收获, 生育期降水 $185.4 \mathrm{~mm}, 2018$ 年 10 至 2019 年 9 月全年降雨量 $716.8 \mathrm{~mm}$ ，小麦 2018 年 10 月 10 日播种, 2019 年 6 月 4 日收获, 生育期降水 $189.1 \mathrm{~mm}$, 小麦生育期日降雨量见图 2。

表 1 试验地 0 60 cm 土层基础理化性状

Table 1 Basic physicochemical properties of the experiment soil $(0-60 \mathrm{~cm})$

\begin{tabular}{cccccccc}
\hline $\begin{array}{c}\text { 土层 } \\
\text { Depth } \\
(\mathrm{cm})\end{array}$ & $\begin{array}{c}\text { 有机质 } \\
\text { Organic matter } \\
\left(\mathrm{g} \mathrm{kg}^{-1}\right)\end{array}$ & $\begin{array}{c}\text { 全氮 } \\
\text { Total } \mathrm{N} \\
\left(\mathrm{g} \mathrm{kg}^{-1}\right)\end{array}$ & $\begin{array}{c}\text { 硝态氮 } \\
\text { Nitrate } \mathrm{N} \\
\left(\mathrm{mg} \mathrm{kg}^{-1}\right)\end{array}$ & $\begin{array}{c}\text { 全磷 } \\
\text { Total P } \\
\left(\mathrm{g} \mathrm{kg}^{-1}\right)\end{array}$ & $\begin{array}{c}\text { 速效磷 } \\
\text { Available P } \\
\left(\mathrm{mg} \mathrm{kg}^{-1}\right)\end{array}$ & $\begin{array}{c}\text { 全钾 } \\
\text { Total K } \\
\left(\mathrm{g} \mathrm{kg}^{-1}\right)\end{array}$ & $\begin{array}{c}\text { 速效钾 } \\
\text { Available K } \\
\left(\mathrm{mg} \mathrm{kg}^{-1}\right)\end{array}$ \\
\hline $0-20$ & 19.06 & 1.24 & 12.46 & 0.99 & 27.59 & 10.85 & 243.87 \\
$20-40$ & 15.03 & 1.00 & 14.53 & 0.86 & 15.06 & 3.54 & 22.31 \\
$40-60$ & 10.95 & 0.79 & 23.08 & 0.62 & 3.59 & 9.90 \\
\hline
\end{tabular}




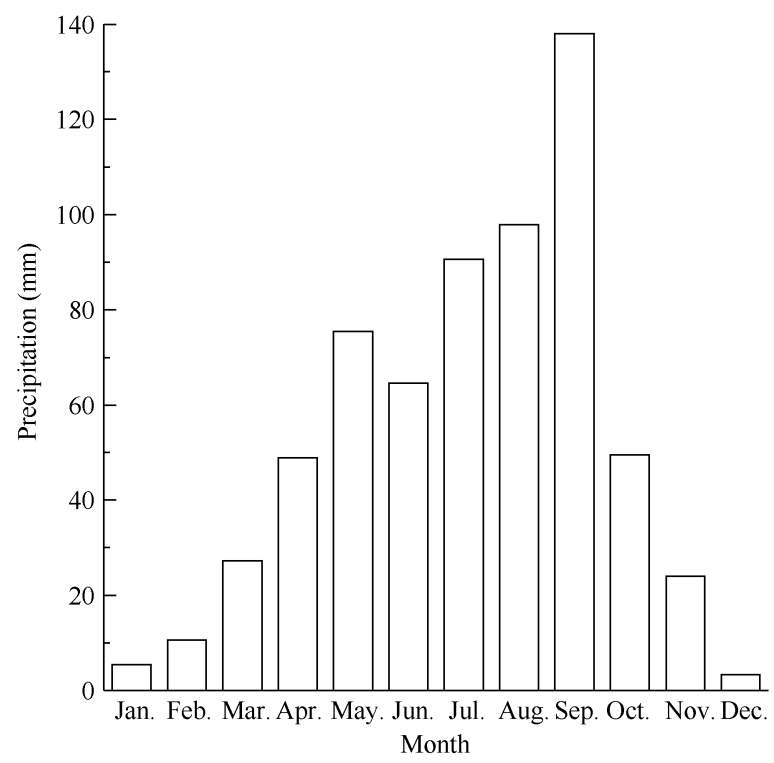

图 1 近 10 年月均降雨量

Fig. 1 Monthly average rainfall in the past 10 years

\section{2 试验设计}

在冬小麦-夏玉米一年二熟制下实施小区连续定 位试验, 采用二因素裂区设计, 氮肥为主处理, 灌水 为副处理, 3 次重复, 小区面积 $6.5 \mathrm{~m} \times 14.0 \mathrm{~m}=$ $91.0 \mathrm{~m}^{2}$ 。设置 5 个施氮量梯度, 以关中平原的高施氮 量 N300 (300 kg hm$\left.)^{-2}\right)$ 为对照, 在此基础上依次按比例 减少施氮量, 减 $25 \%$ 为 $\mathrm{N} 225\left(225 \mathrm{~kg} \mathrm{hm}^{-2}\right)$, 减 $50 \%$ 为 $\mathrm{N} 150\left(150 \mathrm{~kg} \mathrm{hm}^{-2}\right)$, 减 75\%为 N75 $\left(75 \mathrm{~kg} \mathrm{hm}^{-2}\right)$, 全减 为 $\mathrm{N} 0$ (不施氮肥), 氮肥以基追比 7：3 施入, 基肥在小 麦播种前人工均匀撒入, 追肥以同样方式在拔节期施 入。磷肥 $\left(\mathrm{P}_{2} \mathrm{O}_{5}\right) \quad 100 \%$ 基施, 施肥量为 $120 \mathrm{~kg} \mathrm{hm}^{-2}$, 本试验不施钾肥。设置 3 个灌水量水平, 即 $\mathrm{W} 2$ $\left(1200 \mathrm{~m}^{3} \mathrm{hm}^{-2}\right) 、 \mathrm{~W} 1\left(600 \mathrm{~m}^{3} \mathrm{hm}^{-2}\right) 、 \mathrm{~W} 0(0), \mathrm{W} 2$ 于越 冬期和拔节期分 2 次灌入, 每次灌水 $600 \mathrm{~m}^{3} \mathrm{hm}^{-2}, \mathrm{Wl}$ 在越冬期灌溉, W0 不灌溉。供试小麦品种为西农 979, 病虫草害防治等田间管理措施遵照当地农民生产习惯。
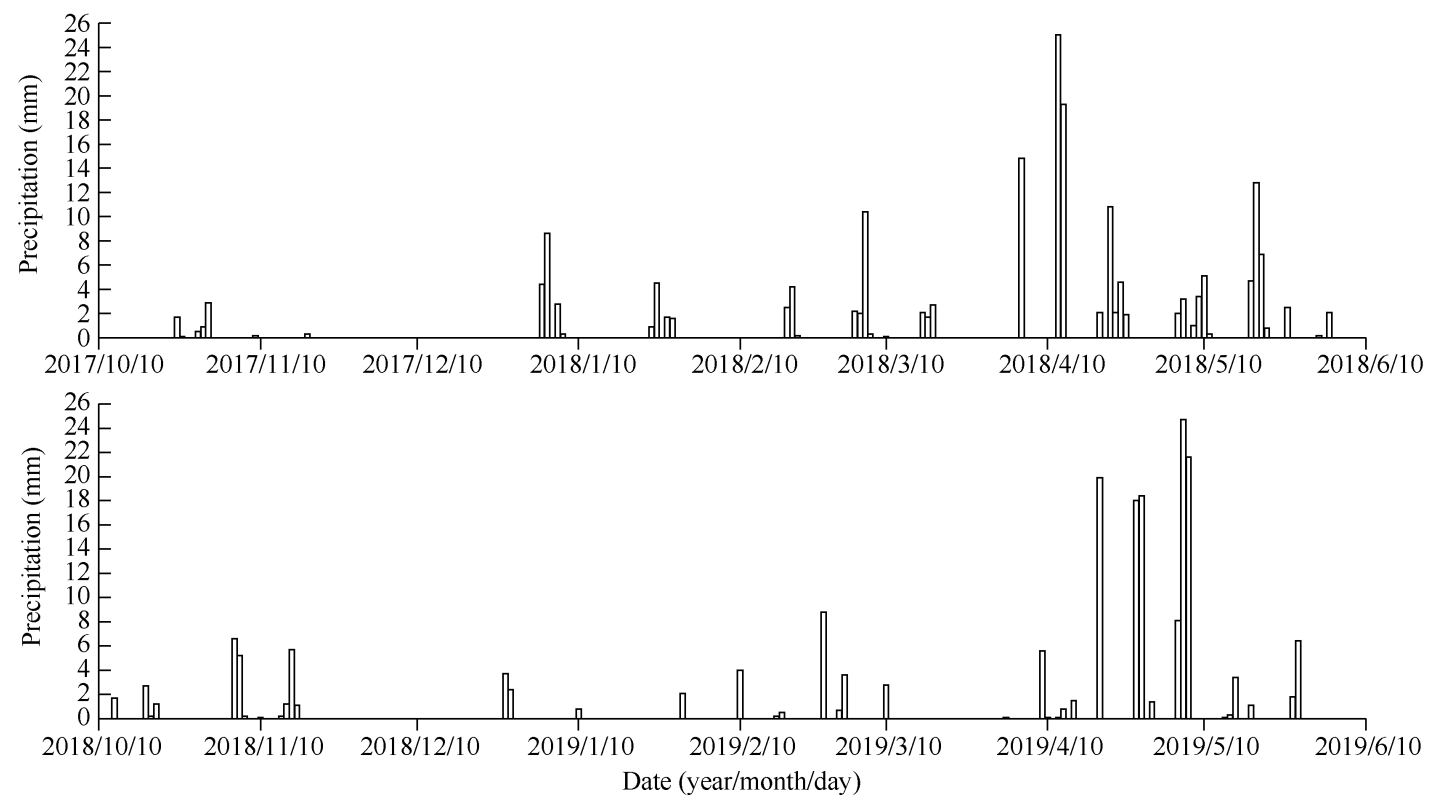

图 2 2017-2019 年小麦生长季日降雨量

Fig. 2 Daily rainfall during wheat growing season from 2017 to 2019

\section{3 测定项目与方法}

1.3.1 生物量测定在小麦成熟期取植株样品测 定生物量, $105^{\circ} \mathrm{C}$ 杀青半小时, $85^{\circ} \mathrm{C}$ 烘至恒重, 称取 植株干物质量, 最后测烘干后的植株氮素含量。

植株氮素积累量=植株含氮量 $(\%) \times$ 干物质的量 1.3.2 产量测定冬小麦收获时, 选择每个处理 3 个 $1 \mathrm{~m} \times 1 \mathrm{~m}$ 样方估产, 取平均值, 室内考种, 调 查穗数、穗粒数和千粒重, 每个处理取 3 个重复。

氮肥农学效率 $\left(\mathrm{NAE}, \mathrm{kg} \mathrm{kg}^{-1}\right)=($ 施氮区产量 不施氮区产量)/施氮量
氮素利用效率 $\left(\mathrm{NUE}, \mathrm{kg} \mathrm{kg}^{-1}\right)=$ 籽粒产量/氮素 积累量

百千克籽粒吸氮量 $\left(\mathrm{kg} \mathrm{hm}^{-2}\right)=$ 植株地上部氮素 积累量/籽粒产量 $\times 100$

1.3.3 土壤水分测定 小麦播种前、收获后以及 各主要生育时期, 用土钻取 $0 \sim 200 \mathrm{~cm}$ 土壤, 每 20 $\mathrm{cm}$ 土样, 装入铝盒, 在 $105^{\circ} \mathrm{C}$ 烘干 $8 \mathrm{~h}$ 至恒重, 计算 土壤含水量。

水分利用效率(WUE, $\mathrm{kg} \mathrm{hm}^{-2} \mathrm{~mm}^{-1}$ ) $=\mathrm{Y} / \mathrm{ET}, \mathrm{Y}$ 为小麦籽粒产量 $\left(\mathrm{kg} \mathrm{hm}^{-2}\right)$, ET 为农田耗水量 $(\mathrm{mm})$ 。 
$\mathrm{ET}=\mathrm{P}+\mathrm{I}+\Delta \mathrm{W}$ ，其中 $\mathrm{P}$ 代表生育期降雨量 $(\mathrm{mm}) ;$ $\mathrm{I}$ 为田间灌水量 $(\mathrm{mm}), \Delta \mathrm{W}$ 为作物播种前与收获后 土壤蓄水变化量 $(\mathrm{mm})$ 。

$\Delta \mathrm{W}(\mathrm{mm})=$ 播前土壤䛎水量一收获后土壤咜水量 1.3.4 土壤养分测定冬小麦播种前和收获后, 测定 $0 \sim 60 \mathrm{~cm}$ 土层土壤有机质、全氮含量以及 0 200 cm 土层土壤硝态氮含量, 每 $20 \mathrm{~cm}$ 土层取样。 采用重铬酸钾外加热法测有机质, 全自动半微量凯 氏定氮法测全氮， $\mathrm{KCl}$ 浸提法测硝态氮，用 $\mathrm{AA} 3$ 型 流动分析仪测定浸提液。本研究中硝态氮淋失量是 80 200 cm 土层内硝态氮积累量。

土壤硝态氮积累量 $=$ 土层厚度 $\times$ 土壤容重 $\times$ 土壤 硝态氮含量 $/ 10$

\section{4 数据统计与分析}

使用 SPSS 19.0 分析试验数据, 采用 Duncan's 法多重比较, 差异显著性水平 $P=0.05$, 使用 Origin 2015 制图。

\section{2 结果与分析}

\section{1 不同水氮处理对冬小麦产量的影响}

表 2 表明，在 2 年试验中，施氮量和灌水量处理 对小麦产量的影响均达到了极显著水平，2017一 2018 年施氮主要通过影响单位面积穗数影响产量, 单位面积穗数随着施氮量增加而增加; 灌水主要影 响单位面积穗数和千粒重, 随着灌水量增加单位面 积穗数增加, 而千粒重反之。2017-2018 年小麦产 量在 $\mathrm{N} 150$ 处理达到最大，继续增施氮肥产量反而 降低，灌水增产效果显著，较不灌水增产 $14.88 \%$ $15.01 \%$ 。2018-2019 年施氮量和灌水量对小麦构成 因素均有显著影响, 随施氮量增加小麦单位面积穗 数增加, 但是穗粒数和千粒重均呈减小趋势, 随灌 水量增加单位面积穗数递增, 但穗粒数和千粒重均 在 $\mathrm{W} 1$ 处理下达到最大，继续灌水反而减小。W0 处 理小麦产量极低甚至濒临绝产，虽随着施氮量增加 产量呈现增加趋势，但是增产幅度并不大，说明干

表 2 施氮和灌水处理对冬小麦产量及其构成因素的影响

Table 2 Effects of nitrogen application and irrigation on winter wheat yield and its components

\begin{tabular}{|c|c|c|c|c|c|c|c|c|}
\hline \multirow[b]{2}{*}{$\begin{array}{c}\text { 处理 } \\
\text { Treatment }\end{array}$} & \multicolumn{4}{|c|}{ 2017-2018 } & \multicolumn{4}{|c|}{ 2018-2019 } \\
\hline & $\begin{array}{c}\text { 穗数 } \\
\mathrm{SN} \\
\left(\times 10^{3} \text { spikes }\right. \\
\left.\mathrm{hm}^{-2}\right)\end{array}$ & $\begin{array}{c}\text { 穗粒数 } \\
\text { GNS }\end{array}$ & $\begin{array}{c}\text { 千粒重 } \\
\text { TGW } \\
\text { (g) }\end{array}$ & $\begin{array}{c}\text { 产量 } \\
\mathrm{GY} \\
\left(\mathrm{kg} \mathrm{hm}^{-2}\right)\end{array}$ & $\begin{array}{c}\text { 穗数 } \\
\mathrm{SN} \\
\left(\times 10^{3} \text { spikes }\right. \\
\left.\mathrm{hm}^{-2}\right)\end{array}$ & $\begin{array}{c}\text { 穗粒数 } \\
\text { GNS }\end{array}$ & $\begin{array}{c}\text { 千粒重 } \\
\text { TGW } \\
(\mathrm{g})\end{array}$ & $\begin{array}{c}\text { 产量 } \\
\text { GY } \\
\left(\mathrm{kg} \mathrm{hm}^{-2}\right)\end{array}$ \\
\hline No & $558.07 \mathrm{c}$ & $37 \mathrm{a}$ & $37.51 \mathrm{a}$ & $6819 \mathrm{c}$ & $327.80 \mathrm{c}$ & $33 \mathrm{a}$ & $45.62 \mathrm{a}$ & $4860 \mathrm{~d}$ \\
\hline N75 & $565.77 \mathrm{bc}$ & $39 \mathrm{a}$ & $37.64 \mathrm{a}$ & $7580 \mathrm{~b}$ & $460.17 \mathrm{ab}$ & $29 \mathrm{~b}$ & $42.11 \mathrm{bc}$ & $5959 \mathrm{c}$ \\
\hline N150 & $599.13 \mathrm{ab}$ & $37 \mathrm{a}$ & $37.73 \mathrm{a}$ & 8092 a & $482.90 \mathrm{a}$ & $29 \mathrm{~b}$ & $42.24 \mathrm{bc}$ & $6599 \mathrm{~b}$ \\
\hline N225 & $596.57 \mathrm{ab}$ & $38 \mathrm{a}$ & $38.46 \mathrm{a}$ & $7578 \mathrm{~b}$ & $467.50 \mathrm{ab}$ & $30 \mathrm{~b}$ & $41.65 \mathrm{c}$ & $7172 \mathrm{a}$ \\
\hline N300 & $607.20 \mathrm{a}$ & $37 \mathrm{a}$ & $36.89 \mathrm{a}$ & $7467 \mathrm{~b}$ & $434.87 \mathrm{~b}$ & $30 \mathrm{~b}$ & $43.44 \mathrm{~b}$ & $6910 \mathrm{ab}$ \\
\hline W0 & $529.76 \mathrm{c}$ & $38 \mathrm{a}$ & $39.84 \mathrm{a}$ & $6827 \mathrm{~b}$ & $392.70 \mathrm{~b}$ & $21 \mathrm{~b}$ & $37.72 \mathrm{c}$ & $1676 \mathrm{~b}$ \\
\hline W1 & $589.38 \mathrm{~b}$ & $38 \mathrm{a}$ & $37.29 \mathrm{~b}$ & $7843 \mathrm{a}$ & $415.36 \mathrm{~b}$ & $36 \mathrm{a}$ & $48.83 \mathrm{a}$ & $8656 \mathrm{a}$ \\
\hline W2 & $636.90 \mathrm{a}$ & $37 \mathrm{a}$ & $35.81 \mathrm{c}$ & 7852 a & $495.88 \mathrm{a}$ & $34 \mathrm{a}$ & $42.94 \mathrm{~b}$ & 8569 a \\
\hline \multicolumn{9}{|l|}{$F$-value } \\
\hline $\mathrm{N}$ & $3.91^{*}$ & $1.21^{\mathrm{NS}}$ & $1.13^{\mathrm{NS}}$ & $15.17^{* * *}$ & $17.66^{* * *}$ & $3.79^{* *}$ & $137.26^{* * *}$ & $29.43^{* * *}$ \\
\hline W & $39.11^{* * *}$ & $1.52^{\mathrm{NS}}$ & $24.69^{* * *}$ & $42.43^{* * *}$ & $22.37^{* * *}$ & $150.77^{* * *}$ & $110.84^{* * *}$ & $922.80^{* * *}$ \\
\hline $\mathrm{N} \times \mathrm{W}$ & $1.71^{\mathrm{NS}}$ & $8.04^{* * *}$ & $4.40^{* *}$ & $5.94^{* * *}$ & $7.56^{* * *}$ & $9.96^{* * *}$ & $2.196^{\mathrm{NS}}$ & $2.14^{\mathrm{NS}}$ \\
\hline
\end{tabular}

N0: 不施氮; $\mathrm{N} 75$ : 施氮量为 $75 \mathrm{~kg} \mathrm{hm}^{-2} ; \mathrm{N} 150$ : 施氮量为 $150 \mathrm{~kg} \mathrm{hm}^{-2}$; N225: 施氮量为 $225 \mathrm{~kg} \mathrm{hm}^{-2} ; \mathrm{N} 300$ : 施氮量为 $300 \mathrm{~kg} \mathrm{hm}$; $\mathrm{W} 0$ : 不灌水; W1: 越冬期灌水 $600 \mathrm{~m}^{3} \mathrm{hm}^{-2}$; W2: 越冬期和拔节期共灌水 $1200 \mathrm{~m}^{3} \mathrm{hm}^{-2}$ 。SN: 穗数; GNS: 穗粒数; TGW: 千粒重; GY: 籽粒 产量。同列标以不同小写字母的值在同一因素不同处理间差异显著 $(P<0.05)$ 。 ${ }^{\mathrm{NS}}$ 表示无显著差异, ${ }^{*}$ 表示 0.05 水平显著, ${ }^{* *}$ 表示 0.01 水 平显著, ${ }^{* * *}$ 表示 0.001 水平显著。

N0: no nitrogen application; N75: N application rate was $75 \mathrm{~kg} \mathrm{hm}^{-2} ; \mathrm{N} 150: \mathrm{N}$ application rate was $150 \mathrm{~kg} \mathrm{hm}^{-2}$; N225: N application rate was $225 \mathrm{~kg} \mathrm{hm}^{-2}$; N300: $\mathrm{N}$ application rate was $300 \mathrm{~kg} \mathrm{hm}^{-2}$; W0: no irrigation; W1: irrigated $600 \mathrm{~m}^{3} \mathrm{hm}^{-2}$ in overwintering period; W2: irrigated $1200 \mathrm{~m}^{3} \mathrm{hm}^{-2}$ in overwintering period and jointing stage. SN: spike number; GNS: grain number per spike; TGW: 1000-grain weight; GY: grain yield. Values followed by different small letters in the same column are significant by different between treatments of the same factor $(P<0.05) .{ }^{\mathrm{NS}}$ means no significant difference; ${ }^{*}$ indicates significant at the 0.05 probability level; ${ }^{* *}$ indicates significant at the 0.01 probability level; ${ }^{* * *}$ indicates significant at the 0.001 probability level. 
旱条件下水分会限制氮肥肥效的发挥, 增施氮肥并 不能达到理想增产效果。2018-2019 年籽粒产量在 $\mathrm{N} 225$ 处理达到最大，但仅比 N150 增产 $8.68 \%$ ，灌水 处理对小麦产量影响极其显著, 灌水较不灌水处理 增产 4.11 4.16 倍。

在同一灌水处理下，2017-2018 和 2018-2019 年小麦产量与施氮量均呈二次曲线关系(图 3)。在 W0 处理下小麦产量已表现出严重减产, 此处暂不 做分析。2017-2018 年 W1 处理下施氮量 $205 \mathrm{~kg} \mathrm{hm}^{-2}$

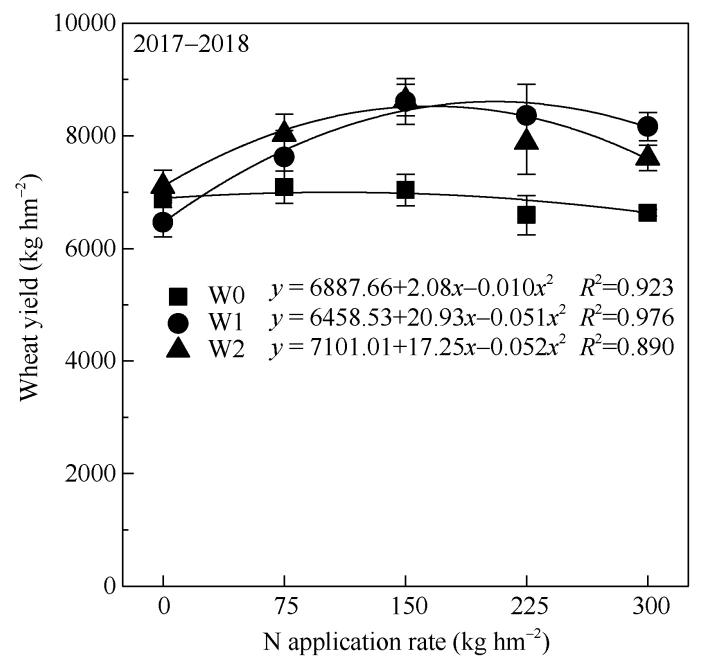

时最高产量可达 $8606 \mathrm{~kg} \mathrm{hm}^{-2}$, W2 处理下施氮量 $168 \mathrm{~kg} \mathrm{hm}^{-2}$ 时最高产量可达 $8532 \mathrm{~kg} \mathrm{hm}^{-2} ; 2018$ 2019 年 $\mathrm{W} 1$ 处理下施氮量 $235 \mathrm{~kg} \mathrm{hm}^{-2}$ 时最高产量可 达 $9492 \mathrm{~kg} \mathrm{hm}^{-2}$, W2 处理下施氮量 $231 \mathrm{~kg} \mathrm{hm}^{-2}$ 时最 高产量可达 $9686 \mathrm{~kg} \mathrm{hm}^{-2}$ 。2017-2018 年即使在最理 想的施氮条件下, 增加灌水反而会使产量略微降低, 2018-2019 年在理想施氮条件下，增加一次灌水小 麦产量虽然增加，但增产效果不显著，仅增产 $2.05 \%$, 说明该地区灌一次水即可满足小麦生长的需求。

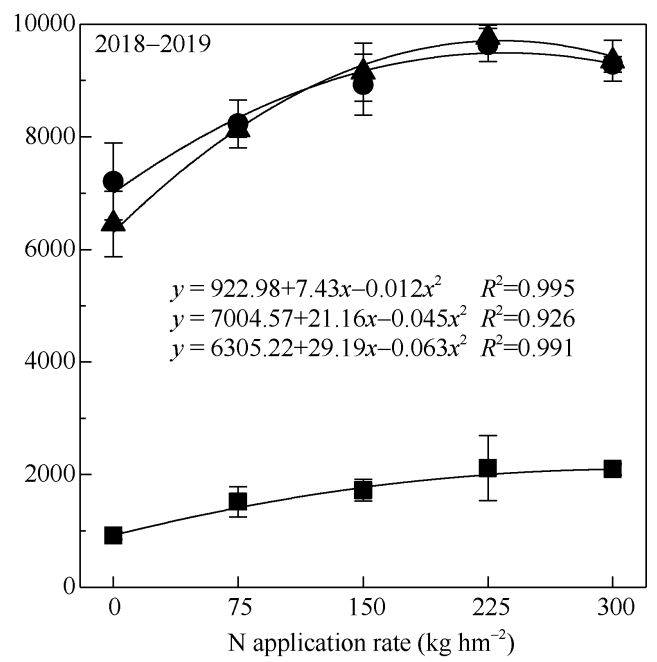

图 3 相同灌水条件下施氮量与小麦产量的关系

Fig. 3 Relationship between nitrogen application rate and wheat yield under the same irrigation conditions

W0: 不灌水; W1: 越冬期灌水 $600 \mathrm{~m}^{3} \mathrm{hm}^{-2} ; \mathrm{W} 2$ : 越冬期和拔节期共灌水 $1200 \mathrm{~m}^{3} \mathrm{hm}^{-2}$ 。

W0: no irrigation; W1: irrigated $600 \mathrm{~m}^{3} \mathrm{hm}^{-2}$ in overwintering period; W2: irrigated $1200 \mathrm{~m}^{3} \mathrm{hm}^{-2}$ in overwintering period and jointing stage.

\section{2 不同水氮处理对冬小麦水氮利用效率的影响}

随着小麦生育期的推进，不同灌水处理下的土 壤水分差异逐渐显现, 同一土层中土壤含水量差异 显著, 整体趋势表现为 $\mathrm{W} 2>\mathrm{W} 1>\mathrm{W} 0$ (图 4)。随着试 验时期延长, W0 处理土壤含水量显著降低, 特别 是 2018 年自小麦播种至孕穗期土壤含水量始终处 于低水平，远不能满足小麦生长所需，使得 2018 年小麦严重减产。表 3 表明, 2017-2018 年施氮量 和灌水量均对冬小麦百千克籽粒吸氮量影响显著,
在同一灌水水平下, 随施氮量增加, 百千克籽粒吸 氮量呈递增趋势, 且 $\mathrm{W} 2>\mathrm{W} 0>\mathrm{W} 1$, 说明同一施氮 水平下, $\mathrm{W} 2$ 处理小麦需要更多的氮肥供应; 2018 2019 年施氮量对冬小麦百千克籽粒吸氮量影响不 显著, W0 和 W2 处理下各施氮水平之间无显著差异, $\mathrm{W} 1$ 处理下冬小麦百千克籽粒吸氮量随施氮量变化 趋势与 2017-2018 年一致, 灌水量对百千克籽粒 吸氮量的影响达到极显著水平, 表现为 $\mathrm{W} 0>\mathrm{W} 2>$ $\mathrm{W} 1$ 。

Soil water content $(\%)$
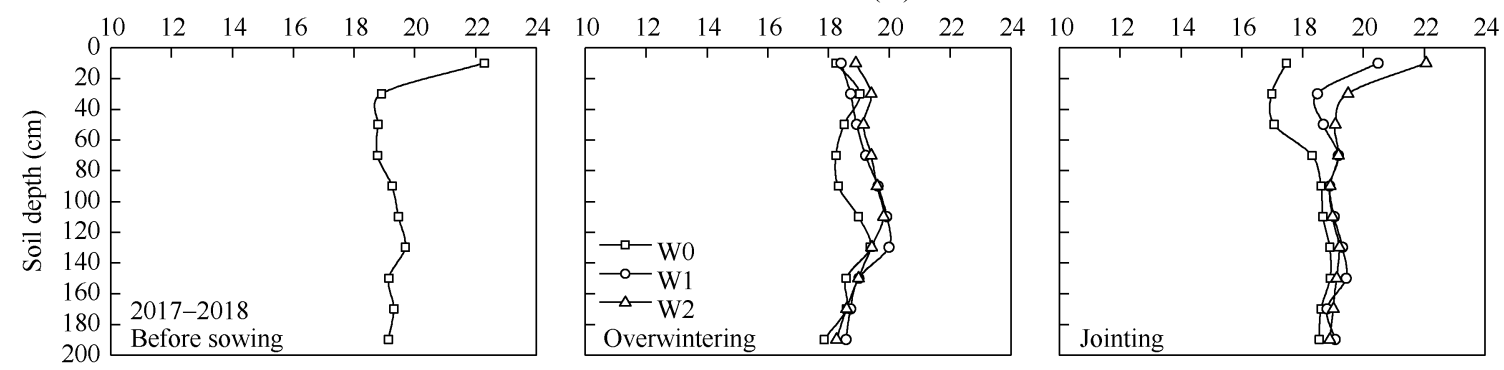

(图 4) 

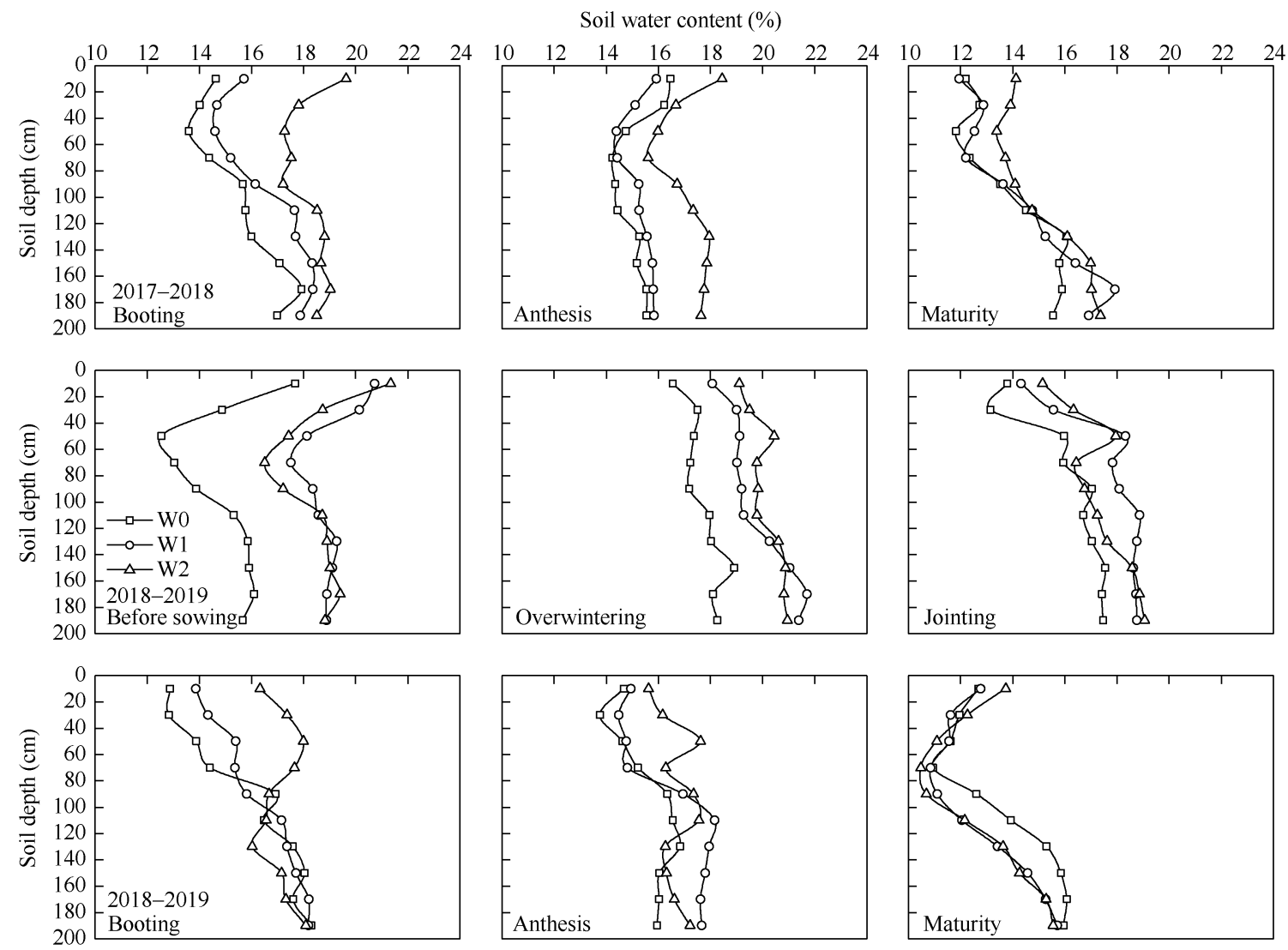

\section{图 4 2017-2019 年小麦季土壤含水量}

Fig. 4 Soil water content of wheat season in 2017-2019

W0: 不灌水; W1: 越冬期灌水 $600 \mathrm{~m}^{3} \mathrm{hm}^{-2} ; \mathrm{W} 2$ : 越冬期和拔节期共灌水 $1200 \mathrm{~m}^{3} \mathrm{hm}^{-2}$ 。

W0: no irrigation; W1: irrigated $600 \mathrm{~m}^{3} \mathrm{hm}^{-2}$ in overwintering period; W2: irrigated $1200 \mathrm{~m}^{3} \mathrm{hm}^{-2}$ in overwintering period and jointing stage.

表 3 不同水氮处理下冬小麦百千克籽粒吸氮量

Table 3 Nitrogen uptake of $100 \mathrm{~kg}$ grain in winter wheat under different water and nitrogen treatments $(\mathrm{kg})$

\begin{tabular}{|c|c|c|c|c|c|c|c|c|}
\hline & \multicolumn{4}{|c|}{$2017-2018$} & \multicolumn{4}{|c|}{ 2018-2019 } \\
\hline & W0 & W1 & W2 & 平均 Mean & W0 & W1 & W2 & 平均 Mean \\
\hline No & $1.65 \mathrm{~d}$ & $2.13 \mathrm{~b}$ & $2.40 \mathrm{~b}$ & $2.06 \mathrm{c}$ & $6.26 \mathrm{a}$ & $1.57 \mathrm{~d}$ & $3.59 \mathrm{a}$ & $3.81 \mathrm{ab}$ \\
\hline N75 & $2.06 \mathrm{~cd}$ & $2.19 \mathrm{~b}$ & $2.48 \mathrm{~b}$ & $2.24 \mathrm{bc}$ & $5.48 \mathrm{a}$ & $1.76 \mathrm{~cd}$ & $3.25 \mathrm{a}$ & $3.50 \mathrm{~b}$ \\
\hline N150 & $2.48 \mathrm{bc}$ & $2.26 \mathrm{~b}$ & $2.55 \mathrm{~b}$ & $2.43 \mathrm{~b}$ & $5.89 \mathrm{a}$ & $2.02 \mathrm{bc}$ & $3.12 \mathrm{a}$ & $3.67 \mathrm{ab}$ \\
\hline N225 & $2.82 \mathrm{ab}$ & $2.48 \mathrm{ab}$ & $3.10 \mathrm{ab}$ & $2.80 \mathrm{a}$ & $5.69 \mathrm{a}$ & $2.24 \mathrm{~b}$ & $3.13 \mathrm{a}$ & $3.68 \mathrm{ab}$ \\
\hline N300 & $3.01 \mathrm{a}$ & $2.75 \mathrm{a}$ & $3.38 \mathrm{a}$ & $3.05 \mathrm{a}$ & $6.37 \mathrm{a}$ & $2.68 \mathrm{a}$ & $3.49 \mathrm{a}$ & $4.18 \mathrm{a}$ \\
\hline 平均 Mean & $2.41 \mathrm{~b}$ & $2.36 \mathrm{~b}$ & $2.78 \mathrm{a}$ & - & $5.94 \mathrm{a}$ & $2.05 \mathrm{c}$ & $3.31 \mathrm{~b}$ & - \\
\hline \multicolumn{9}{|l|}{$F$-value } \\
\hline $\mathrm{N}$ & \multicolumn{4}{|c|}{$16.87^{* * *}$} & \multicolumn{4}{|c|}{$2.11^{\mathrm{NS}}$} \\
\hline W & \multicolumn{4}{|c|}{$9.31^{* *}$} & \multicolumn{4}{|c|}{$212.65^{* * *}$} \\
\hline $\mathrm{N} \times \mathrm{W}$ & \multicolumn{4}{|c|}{$1.26^{\mathrm{NS}}$} & \multicolumn{4}{|c|}{$0.97^{\mathrm{NS}}$} \\
\hline
\end{tabular}

N0: 不施氮; $\mathrm{N} 75$ : 施氮量为 $75 \mathrm{~kg} \mathrm{hm}^{-2} ; \mathrm{N} 150$ : 施氮量为 $150 \mathrm{~kg} \mathrm{hm}^{-2} ; \mathrm{N} 225$ : 施氮量为 $225 \mathrm{~kg} \mathrm{hm}^{-2} ; \mathrm{N} 300$ : 施氮量为 $300 \mathrm{~kg} \mathrm{hm}{ }^{-2}$; W0: 不灌水; W1: 越冬期灌水 $600 \mathrm{~m}^{3} \mathrm{hm}^{-2} ; \mathrm{W} 2$ : 越冬期和拔节期共灌水 $1200 \mathrm{~m}^{3} \mathrm{hm}^{-2}$ 。标以不同小写字母的值在同一灌水条件下施氮量之 间的差异显著 $(P<0.05)$, 平均值后不同字母表示同一因素不同处理间差异显著 $(P<0.05)$ 。 ${ }^{\mathrm{NS}}$ 表示无显著差异, ${ }^{*}$ 表示 0.05 水平显著, ${ }^{* *}$ 表示 0.01 水平显著, ${ }^{* * *}$ 表示 0.001 水平显著。

N0: no nitrogen application; N75: N application rate was $75 \mathrm{~kg} \mathrm{hm}^{-2} ; \mathrm{N} 150: \mathrm{N}$ application rate was $150 \mathrm{~kg} \mathrm{hm}^{-2}$; N225: N application rate was $225 \mathrm{~kg} \mathrm{hm}^{-2}$; N300: $\mathrm{N}$ application rate was $300 \mathrm{~kg} \mathrm{hm}^{-2}$; W0: no irrigation; W1: irrigated $600 \mathrm{~m}^{3} \mathrm{hm}^{-2}$ in overwintering period; W2: irrigated $1200 \mathrm{~m}^{3} \mathrm{hm}^{-2}$ in overwintering period and jointing stage. Values followed by different lowercase letters are significantly different between nitrogen application rates under the same irrigation conditions $(P<0.05)$, means followed by different letters are significantly different between different treatments of the same factor $(P<0.05)$. ${ }^{\mathrm{NS}}$ means no significant difference; ${ }^{*}$ indicates significant at the 0.05 probability level; ${ }^{* *}$ indicates significant at the 0.01 probability level; ${ }^{* * *}$ indicates significant at the 0.001 probability level. 
表 4 表明, 在同一灌水处理下, 随着施氮量增 加, 氮肥农学效率逐渐降低, W0、W1 和 W2 条件下 表现出相同的趋势，但同一施氮水平下 2017-2018 年氮肥农学效率表现为 $\mathrm{W} 1>\mathrm{W} 2>\mathrm{W} 0$ 且差异显著, W1 条件下 N75 和 N150 显著优于其他处理, 20182019 年表现为 W2 $>W 1>W 0$, 且 W2 处理下的氮肥农 学效率显著优于 $\mathrm{W} 1$; 氮素利用效率随施氮量变化 规律与氮肥农学效率类似, 即同一灌水处理下随着 施氮量的增加而减小，2017-2018 年氮肥利用效率 则是 N0、N75 条件下 W0 处理较高, 而 N150、N225、
N300 条件下 W1 处理较高, 2018-2019 年在 W1 处 理下更显优势。水分利用效率随着施氮量的增加呈 现先增加后减小的趋势，2017-2018 年 3 种灌水水 平下均在 N150 处理下水分利用效率最大, 且三者 之间差异不显著; 2018-2019 年则是在 N225 处理下 水分利用效率最大, 与 $\mathrm{N} 150$ 处理下无显著差异, 但 W2 和 W1 处理下水分利用显著优于 W0 处理, 表现 为 $\mathrm{W} 1>\mathrm{W} 2>\mathrm{W} 0$ 。2 年试验结果表明, $\mathrm{W} 1$ 处理既可满 足小麦生长需求, 获得较好的氮肥利用效率, 又可 以在不浪费水资源的基础上高效利用水分。

表 4 不同水氮处理对小麦水氮利用效率的影响

Table 4 Effect of different treatments on water and nitrogen use efficiencies of wheat

\begin{tabular}{|c|c|c|c|c|c|c|}
\hline \multirow[b]{2}{*}{$\begin{array}{c}\text { 处理 } \\
\text { Treatment }\end{array}$} & \multicolumn{3}{|c|}{ 2017-2018 } & \multicolumn{3}{|c|}{ 2018-2019 } \\
\hline & $\begin{array}{c}\text { 氮肥农学 } \\
\text { 效率 } \\
\text { NAE } \\
\left(\mathrm{kg} \mathrm{kg}^{-1}\right)\end{array}$ & $\begin{array}{c}\text { 氮素利用效率 } \\
\text { NUE } \\
\left(\mathrm{kg} \mathrm{kg}^{-1}\right)\end{array}$ & $\begin{array}{c}\text { 水分利用效率 } \\
\text { WUE } \\
\left(\mathrm{kg} \mathrm{hm}^{-2} \mathrm{~mm}^{-1}\right)\end{array}$ & $\begin{array}{c}\text { 氮肥农学效率 } \\
\text { NAE } \\
\left(\mathrm{kg} \mathrm{kg}^{-1}\right)\end{array}$ & $\begin{array}{c}\text { 氮素利用效率 } \\
\text { NUE } \\
\left(\mathrm{kg} \mathrm{kg}^{-1}\right)\end{array}$ & $\begin{array}{c}\text { 水分利用效率 } \\
\text { WUE } \\
\left(\mathrm{g} \mathrm{hm}^{-2} \mathrm{~mm}^{-1}\right)\end{array}$ \\
\hline W0N0 & - & $59.20 \mathrm{a}$ & $18.67 \mathrm{~cd}$ & - & $15.98 \mathrm{f}$ & $4.91 \mathrm{~h}$ \\
\hline W0N75 & 2.89 ef & $48.62 \mathrm{~b}$ & $20.11 b c$ & $7.97 \mathrm{fg}$ & $18.28 \mathrm{f}$ & $6.04 \mathrm{gh}$ \\
\hline W0N150 & $0.99 \mathrm{f}$ & $40.43 \mathrm{de}$ & $22.65 \mathrm{a}$ & $5.36 \mathrm{gh}$ & $17.03 \mathrm{f}$ & $7.58 \mathrm{fg}$ \\
\hline W0N225 & $-1.76 \mathrm{~g}$ & $35.69 \mathrm{fg}$ & $18.66 \mathrm{~cd}$ & $5.31 \mathrm{gh}$ & $17.59 \mathrm{f}$ & $9.02 \mathrm{f}$ \\
\hline W0N300 & $-0.85 \mathrm{~g}$ & $33.31 \mathrm{gh}$ & $20.41 \mathrm{bc}$ & $3.92 \mathrm{gh}$ & $15.90 \mathrm{f}$ & $8.02 \mathrm{f}$ \\
\hline W1N0 & - & $46.93 \mathrm{~b}$ & $18.11 \mathrm{~d}$ & - & $63.65 \mathrm{a}$ & $18.03 \mathrm{~cd}$ \\
\hline W1N75 & $15.45 \mathrm{a}$ & $45.82 \mathrm{bc}$ & $20.13 b c$ & $13.65 \mathrm{~cd}$ & $56.87 \mathrm{~b}$ & $18.33 \mathrm{~cd}$ \\
\hline W1N150 & $14.29 \mathrm{a}$ & $44.91 \mathrm{bc}$ & $21.16 \mathrm{ab}$ & $11.44 \mathrm{de}$ & $49.52 \mathrm{c}$ & $20.01 \mathrm{bc}$ \\
\hline W1N225 & $8.42 \mathrm{c}$ & $40.53 \mathrm{de}$ & $20.38 \mathrm{bc}$ & $10.78 \mathrm{e}$ & $45.09 \mathrm{c}$ & $22.35 \mathrm{a}$ \\
\hline W1N300 & $5.66 \mathrm{~d}$ & 36.50 efg & $21.07 \mathrm{ab}$ & $6.93 \mathrm{fg}$ & $37.42 \mathrm{~d}$ & $21.89 \mathrm{a}$ \\
\hline W2N0 & - & $41.90 \mathrm{~cd}$ & $16.85 \mathrm{~d}$ & - & $27.95 \mathrm{e}$ & $14.06 \mathrm{e}$ \\
\hline W2N75 & $12.32 \mathrm{~b}$ & $40.73 \mathrm{de}$ & $17.59 \mathrm{~d}$ & $22.36 \mathrm{a}$ & $30.82 \mathrm{e}$ & $17.04 \mathrm{~d}$ \\
\hline W2N150 & $10.19 \mathrm{c}$ & $39.22 \mathrm{def}$ & $21.15 \mathrm{ab}$ & $17.98 \mathrm{~b}$ & $32.98 \mathrm{de}$ & $19.89 \mathrm{bc}$ \\
\hline W2N225 & $3.47 \mathrm{e}$ & $32.54 \mathrm{gh}$ & $18.47 \mathrm{~cd}$ & $14.72 \mathrm{c}$ & $32.85 \mathrm{de}$ & $21.21 \mathrm{ab}$ \\
\hline W2N300 & $1.67 \mathrm{ef}$ & $29.90 \mathrm{~h}$ & $17.82 \mathrm{~d}$ & $9.65 \mathrm{ef}$ & $28.83 \mathrm{e}$ & $19.88 \mathrm{bc}$ \\
\hline \multicolumn{7}{|l|}{$F$-value } \\
\hline $\mathrm{N}$ & $121.95^{* * *}$ & $63.92^{* * *}$ & $16.07^{* * *}$ & $38.48^{* * *}$ & $9.94^{* * *}$ & $35.38^{* * *}$ \\
\hline W & $310.08^{* * *}$ & $33.89^{* * *}$ & $14.42^{* * *}$ & $135.53^{* * *}$ & $408.77^{* * *}$ & $657.46^{* * *}$ \\
\hline $\mathrm{N} \times \mathrm{W}$ & $8.83^{* * *}$ & $8.07^{* * *}$ & $1.90^{\mathrm{NS}}$ & $4.81^{* *}$ & $10.83^{* * *}$ & $1.84^{\mathrm{NS}}$ \\
\hline
\end{tabular}

$\mathrm{N} 0$ : 不施氮; $\mathrm{N} 75$ : 施氮量为 $75 \mathrm{~kg} \mathrm{hm}^{-2} ; \mathrm{N} 150$ : 施氮量为 $150 \mathrm{~kg} \mathrm{hm}^{-2}$; N225: 施氮量为 $225 \mathrm{~kg} \mathrm{hm}^{-2} ; \mathrm{N} 300$ : 施氮量为 $300 \mathrm{~kg} \mathrm{hm}{ }^{-2}$; W0: 不灌水; W1: 越冬期灌水 $600 \mathrm{~m}^{3} \mathrm{hm}^{-2}$; W2: 越冬期和拔节期共灌水 $1200 \mathrm{~m}^{3} \mathrm{hm}^{-2}, \mathrm{NAE}$ : 氮肥农学效率; NUE: 氮肥利用效率; WUE: 水分利用效率。同列标以不同字母的值不同处理间在 0.05 水平上显著差异 $(P<0.05)$ 。 ${ }^{\mathrm{N}}$ 表示无显著差异, ${ }^{*}$ 表示 0.05 水平显著, ${ }^{* *}$ 表示 0.01 水平显著, ${ }^{* * *}$ 表示 0.001 水平显著。

$\mathrm{N} 0$ : no nitrogen application; N75: N application rate was $75 \mathrm{~kg} \mathrm{hm}^{-2} ; \mathrm{N} 150: \mathrm{N}$ application rate was $150 \mathrm{~kg} \mathrm{hm}^{-2} ; \mathrm{N} 225: \mathrm{N}$ application rate was $225 \mathrm{~kg} \mathrm{hm}^{-2}$; N300: $\mathrm{N}$ application rate was $300 \mathrm{~kg} \mathrm{hm}^{-2}$; W0: no irrigation; W1: irrigated $600 \mathrm{~m}^{3} \mathrm{hm}^{-2}$ in overwintering period; W2: irrigated $1200 \mathrm{~m}^{3} \mathrm{hm}^{-2}$ in overwintering period and jointing stage; NAE: nitrogen agronomic efficiency; NUE: nitrogen use efficiency; WUE: water use efficiency. Values followed by different letters in the same column are significantly different at $P<0.05$ between different treatments. ${ }^{\text {NS }}$ means no significant difference; ${ }^{*}$ indicates significant at the 0.05 probability level; ${ }^{* *}$ indicates significant at the 0.01 probability level; ${ }^{* * *}$ indicates significant at the 0.001 probability level. 
2.3 不同水氮处理对土壤硝态氮含量及其淋失 的影响

图 5 表明，相同灌水处理下，麦田 $0 \sim 200 \mathrm{~cm}$ 土 层土壤硝态氮含量随施氮量增加呈递增趋势, 并且 施氮处理土壤硝态氮含量显著高于不施氮处理，表 明施氮显著增加了土壤硝态氮含量，氮肥施用量越 高则土壤中硝态氮含量越高。从灌水处理看, 在 W0 处理下随着土层加深, 硝态氮含量逐渐减少, 而在 $\mathrm{W} 1$ 和 $\mathrm{W} 2$ 处理下, 随着土层加深硝态氮含量 逐渐增大, $\mathrm{W} 0$ 处理 $0 \sim 60 \mathrm{~cm}$ 土层硝态氮含量显著高 于 $\mathrm{W} 1$ 、 $\mathrm{W} 2$ 处理, 而 $\mathrm{W} 1$ 和 $\mathrm{W} 2$ 处理 $60 \sim 200 \mathrm{~cm}$ 土 层的硝态氮含量显著高于 $\mathrm{W} 0$ 处理, 说明随着灌水 量增加, 土壤剖面中硝态氮会随着水分向下层土壤
迁移。在 W1 处理下, N0、N75 和 N150 处理土壤 剖面硝态氮含量始终处在一个相对较低的水平, 而 当施氮量大于 $150 \mathrm{~kg} \mathrm{hm}^{-2}$ 后深层土壤硝态氮含量 显著增高; 在 W2 处理下, 2017-2018 年 $60 \mathrm{~cm}$ 以 下土层硝态氮含量均处于较高水平, 并且随着土层 加深硝态氮含量增大, 深层土壤中硝态氮大量累积, 2018 -2019 年虽然 60 160 cm 土层的硝态氮含量 处在较低水平, 但 $160 \mathrm{~cm}$ 以下硝态氮含量骤增, 这 可能是由于灌水使硝态氮往更深层土壤中迁移。说 明施氮量和灌水量显著影响硝态氮在土壤的累积 和迁移，在相同灌水处理下，施氮量增加，土壤中 硝态氮含量随之增加，而随着灌水增多，硝态氮向 下迁移加快。

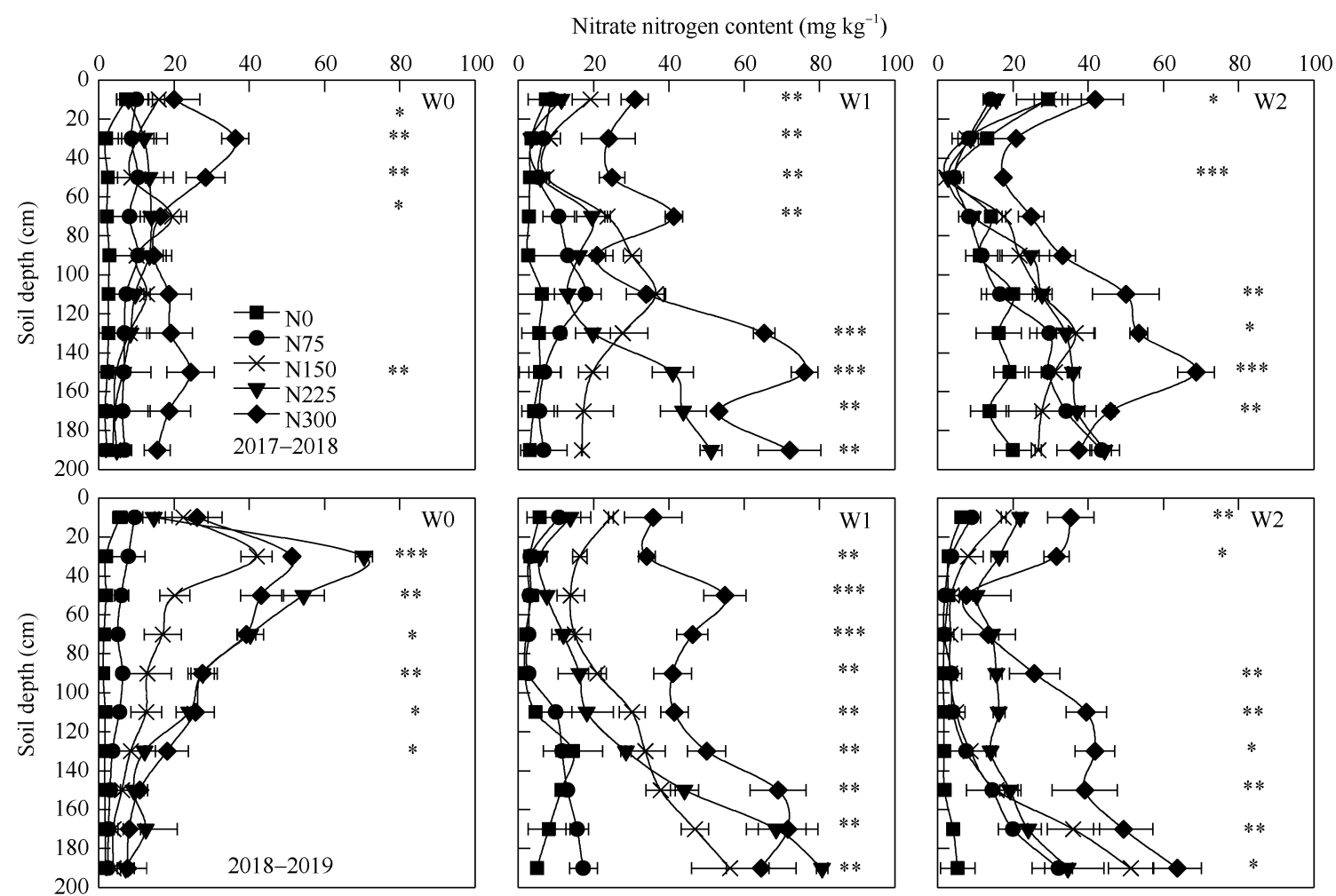

图 $52017-2019$ 年小麦收获后 $0 \sim 200 \mathrm{~cm}$ 土层土壤硝态氮含量剖面图

Fig. 5 Soil nitrate nitrogen content in $0-200 \mathrm{~cm}$ profile after wheat harvest in 2017-2019

W0: 不灌水; W1: 越冬期灌水 $600 \mathrm{~m}^{3} \mathrm{hm}^{-2}$; W2: 越冬期和拔节期共灌水 $1200 \mathrm{~m}^{3} \mathrm{hm}^{-2}$ 。表示 0.05 水平显著; **表示 0.01 水平显著; *** 表示 0.001 水平显著。

W0: no irrigation; W1: irrigated $600 \mathrm{~m}^{3} \mathrm{hm}^{-2}$ in overwintering period; W2: irrigated $1200 \mathrm{~m}^{3} \mathrm{hm}^{-2}$ in overwintering period and jointing stage. * indicates significant at the 0.05 probability level; $* *$ indicates significant at the 0.01 probability level; $* * *$ indicates significant at the 0.001 probability level.

由图 6 可知，随着施氮量增加，2017-2018 年和 2018 -2019 年麦田土壤硝态氮淋失量均增大, 这说 明增加施氮会加剧硝态氮淋溶风险; 而随着灌水量 增加, 2017-2018 年除 N300+W2 处理外, 其他均是 $\mathrm{W} 2>\mathrm{W} 1>\mathrm{W} 0,2018$-2019 年麦田土壤硝态氮淋失量
表现为 $\mathrm{W} 1>\mathrm{W} 2>\mathrm{W} 0$, 但是从各土层中硝态氮含量 分析, 2018-2019 年 W2 处理在 $160 \mathrm{~cm}$ 以下土层土 壤硝态氮含量骤增, 可能是灌水的作用使硝态氮积 累峰下移。在相同施氮量, 且 $60 \mathrm{~cm}$ 土层之下的硝 态氮不易被作物吸收利用条件下, 2018-2019年 W2 

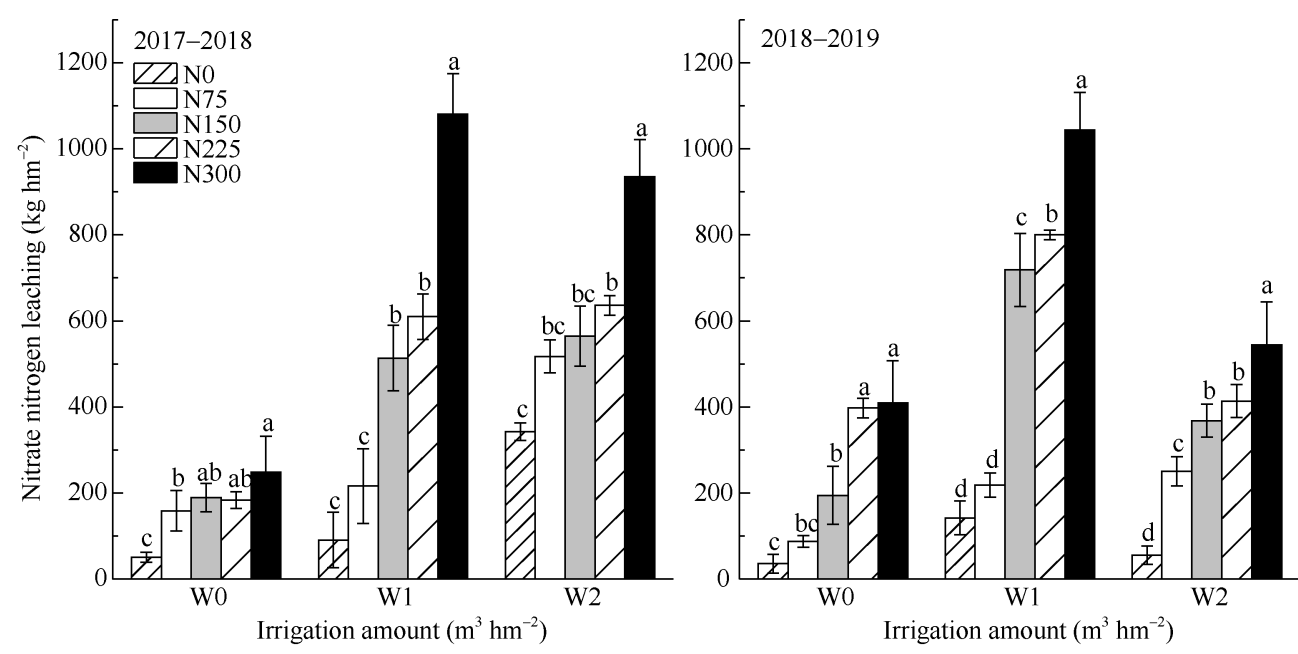

图 6 不同水氮处理下麦田土壤硝态氮淋失量

Fig. 6 Nitrate nitrogen leaching under different treatments

N0: 不施氮; N75: 施氮量为 $75 \mathrm{~kg} \mathrm{hm}^{-2} ; \mathrm{N} 150$ : 施氮量为 $150 \mathrm{~kg} \mathrm{hm}^{-2} ; \mathrm{N} 225$ : 施氮量为 $225 \mathrm{~kg} \mathrm{hm}^{-2} ; \mathrm{N} 300$ : 施氮量为 $300 \mathrm{~kg} \mathrm{hm}$; W0: 不灌水; W1: 越冬期灌水 $600 \mathrm{~m}^{3} \mathrm{hm}^{-2} ; \mathrm{W} 2$ : 越冬期和拔节期共灌水 $1200 \mathrm{~m}^{3} \mathrm{hm}^{-2}$ 。柱上不同小写字母表示在同一水分条件下在 0.05 水平上有显著性差异 $(P<0.05)$ 。

N0: no nitrogen application; N75: N application rate was $75 \mathrm{~kg} \mathrm{hm}^{-2} ; \mathrm{N} 150: \mathrm{N}$ application rate was $150 \mathrm{~kg} \mathrm{hm}^{-2} ; \mathrm{N} 225: \mathrm{N}$ application rate was $225 \mathrm{~kg} \mathrm{hm}^{-2}$; N300:N application rate was $300 \mathrm{~kg} \mathrm{hm}^{-21}$; W0: no irrigation; W1: irrigated $600 \mathrm{~m}^{3} \mathrm{hm}^{-2}$ in overwintering period; W2: irrigated $1200 \mathrm{~m}^{3} \mathrm{hm}^{-2}$ in overwintering period and jointing stage. Different letters above the bar mean significant differences at the 0.05 probability level under the same irrigation condition.

处理下土壤硝态氮淋失量反而显著低于 2017-2018 年, 从侧面印证了这个观点。

\section{4 水氮处理下冬小麦产量、氮肥利用效率和硝} 态淋失量的关系

为了寻求协调作物高产和环境保护的氮肥投入 阈值, 本研究以冬小麦产量作为产出指标, 以氮肥 利用效率和硝态氮淋失量作为环境指标进行多曲线 分析。前文分析得出, 在 W1 处理下产量、水分利用 和施氮对环境效应可以得到一个相对满意的结果, 此处只对 W1 处理下小麦产量、氮肥利用效率和硝 态氮淋失情况进行分析。根据图 7 呈现的结果, 综 合考虑小麦产量、氮肥利用效率以及硝态氮淋失量, 2017 -2018 年施氮量 $150 \mathrm{~kg} \mathrm{hm}^{-2}$ 最为合适, 根据公 式拟合出施氮 $205 \mathrm{~kg} \mathrm{hm}^{-2}$ 时产量最大 $8605 \mathrm{~kg} \mathrm{hm}^{-2}$, 但实际生产中施氮 $150 \mathrm{~kg} \mathrm{hm}^{-2}$ 便可以达到这个产量, 同时氮肥能得到高效利用, 硝态氮淋失量也较施氮 $205 \mathrm{~kg} \mathrm{hm}^{-2}$ 时减少 $29.6 \% ; 2018$-2019 年施氮量 $150 \mathrm{~kg} \mathrm{hm}^{-2}$ 时产量为 $8922 \mathrm{~kg} \mathrm{hm}^{-2}$, 比实际生产中 施氮 $225 \mathrm{~kg} \mathrm{hm}^{-2}$ 条件下的产量仅降低了 $7.4 \%$, 比拟 合中最大产量低 $6.0 \%$, 氮肥利用程度却有提升, 且 比拟合条件下硝态氮淋失量减少了 $42 \%$ 左右。两年 试验中施氮 $150 \mathrm{~kg} \mathrm{hm}^{-2}$ 处理下硝态氮淋失量较施氮 $225 \mathrm{~kg} \mathrm{hm}^{-2}$ 分别降低了 $15.87 \%$ 和 $10.20 \%$ 。因此, 综 合考虑小麦产量、肥料利用和环境效应, 推荐麦田
施氮量为 $150 \mathrm{~kg} \mathrm{hm}^{-2}$ 。

\section{3 讨论}

\section{1 水氮处理下冬小麦产量及水氮利用情况}

前人研究指出, 氮素和水分是影响作物生长的 重要因素, 小麦对氮素的吸收必须以水为媒介, 而 干旱条件下增施氮肥, 能增强植物抗旱性, 缓解水 分胁迫对植株生长和产量的不利影响 ${ }^{[26-27]}$ 。本试验 W0 处理下, 2017-2018 年时施氮 $75 \mathrm{~kg} \mathrm{hm}^{-2}$ 产量最 高，增施氮肥产量反而降低，2018-2019 年产量随 施氮增加虽有增长但相比第一年严重下降, 且当施 氮量大于 $225 \mathrm{~kg} \mathrm{hm}^{-2}$ 后产量降低。这与前人结果不 一致, 可能是因为干旱程度不一致, 本试验 $2017-$ 2018 年小麦播前土壤咜水量为 $563.48 \mathrm{~mm}$, 2018-2019 年小麦播前不灌水处理下由于经历过小 麦和玉米的生长且作物整个生长过程中没有人工补 充水分, 土壤䛎水量仅为 $436.29 \mathrm{~mm}$, 且小麦需水关 键期(越冬期至孕穗期)降水不足, 造成土壤干旱。轻 度干旱条件下增施氮肥可以缓解水分不足的影响, 但当干旱相对严重时, 过量施氮反而加剧了干旱程 度, 导致小麦产量降低, 虽然小麦生育后期降雨增 多, 部分小麦解除干旱抑制, 重新抽穗, 但时间过 晚来不及灌浆, 属于无效穗数, 并不能增加产量, 反而使百千克籽粒吸氮量骤增, 不利于氮肥高效利 

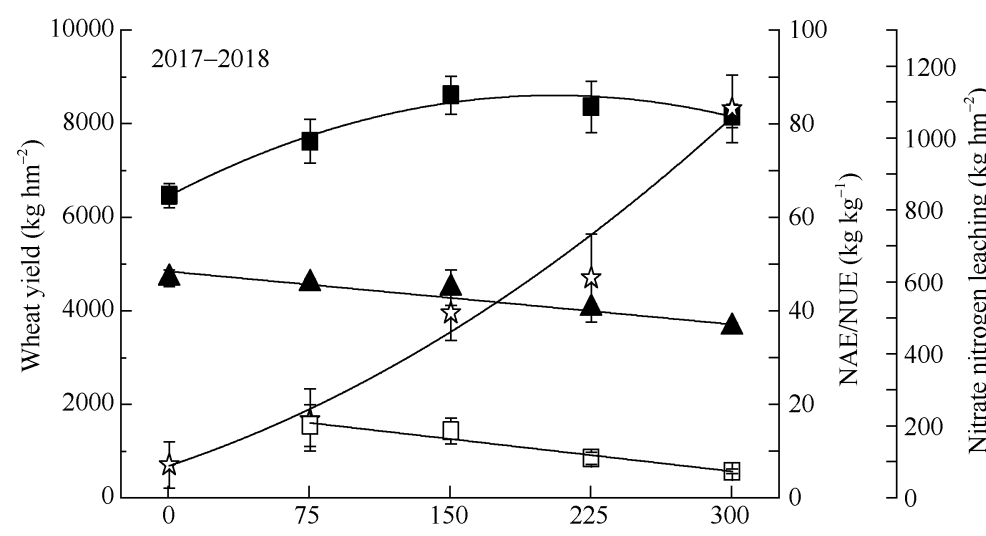

Wheat yield

$y=6458.53+20.93 x-0.051 x^{2} \quad R^{2}=0.976$

$\square$ NAE

$y=19.47-0.046 x \quad R^{2}=0.941$

$\Delta \mathrm{NUE}$

$y=48.40-0.038 x \quad R^{2}=0.958$

is Nitrate nitrogen leaching

$y=89.42+1.72 x+0.005 x^{2} \quad R^{2}=0.965$
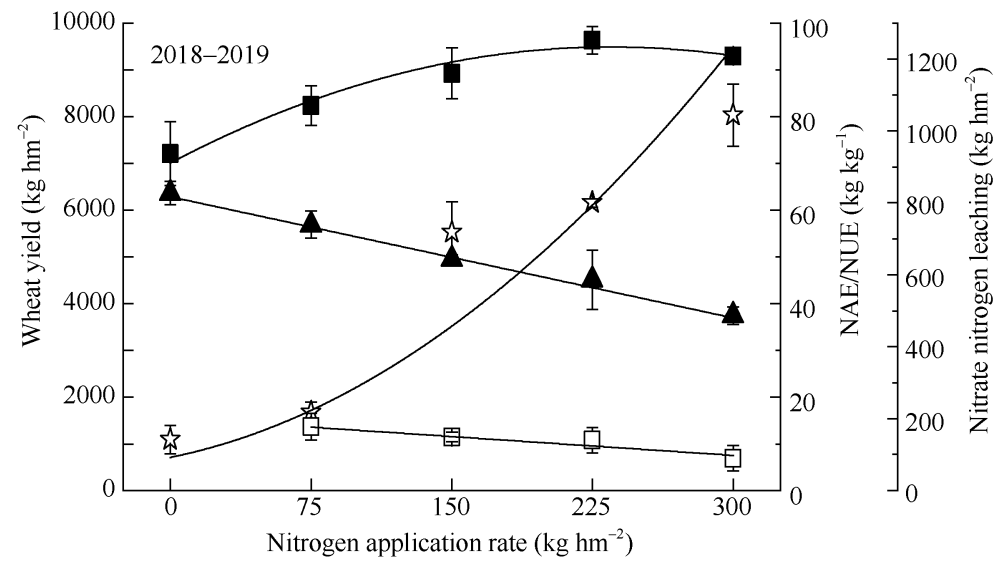

Wheat yield

$y=7004.57+21.16 x-0.045 x^{2} \quad R^{2}=0.926$

$\square \mathrm{NAE}$

$y=15.57-0.027 x \quad R^{2}=0.877$

$\Delta \mathrm{NUE}$

$y=62.84-0.086 x R^{2}=0.993$

Nitrate nitrogen leaching $y=92.14+1.056 x+0.009 x^{2} R^{2}=0.981$

图 7 不同施氮量处理下小麦产量与氮肥利用和硝态氮淋失的关系

Fig. 7 Relationship of wheat yield with nitrogen use and nitrate leaching under different nitrogen application rates

NAE: 氮肥农学效率; NUE: 氮肥利用效率。

NAE: nitrogen agronomic efficiency; NUE: nitrogen use efficiency.

用。因此该地区应该在小麦生育期灌水，避免严重 减产。在 W1 与 W2 处理下小麦产量差别并不显著, 但 $\mathrm{W} 1$ 处理下的百千克籽粒吸氮量显著低于 W2 处 理，两年间分别降低 $0.27 \sim 0.63 \mathrm{~kg} 、 0.81 \sim 2.02 \mathrm{~kg}$ 。 W2 处理虽然增加了小麦单位面积穗数, 但由于小 麦群体过大, 穗粒数和千粒重显著降低, 甚至 N225 和 N300 处理部分区域发生小麦倒伏现象，使得最 终的产量并没有显著提升, 且拟合方程显示, 在理 想施氮条件下, 灌两水处理的产量并没有表现出显 著优势, 即该地区小麦季灌一水已基本满足作物生 长的水分需求, 可获得较高的产量, 增加灌水, 产 量没有大幅提升, 反而降低了水分利用率, 浪费水 资源。

1978-2006 年间化肥投入对粮食产量增长的贡 献率达 $56.81 \%$, 氮肥是主要因素, 对粮食增产的贡 献率高达 $40 \%{ }^{[28-29]}$, 农业生产中多通过增大施氮量 来提高产量, 然而实际生产中, 作物产量并非随施氮 量的增加成比例增加，反而呈现出报酬递减规律 ${ }^{[30]}$ 。 徐凤娇研究表明, 施氮量控制在 180 270 $\mathrm{kg} \mathrm{hm}^{-2}$ 范
围内, 可以有效提高产量, 超过 $270 \mathrm{~kg} \mathrm{hm}^{-2}$ 时产量 开始下降 ${ }^{[31]}$; 本试验结果与此一致, 2017- 2018 年 $\mathrm{W} 1$ 处理下施氮量 $150 \mathrm{~kg} \mathrm{hm}^{-2}$ 即可获得最大产量, 百千克籽粒吸氮量较施氮量 $225 \mathrm{~kg} \mathrm{hm}^{-2}$ 降低 0.22 $\mathrm{kg}$, NAE 和 NUE 分别比施氮 $225 \mathrm{~kg} \mathrm{hm}^{-2}$ 处理提高 $5.87 \mathrm{~kg} \mathrm{~kg}^{-1} 、 4.38 \mathrm{~kg} \mathrm{~kg}^{-1}, 2018$-2019 年施氮量 225 $\mathrm{kg} \mathrm{hm}^{-2}$ 即可获得最大产量, 在此基础上增加施氮量 时, 产量反而有降低趋势。但 2018-2019 年 W1 处 理施氮量 $225 \mathrm{~kg} \mathrm{hm}^{-2}$ 仅比施氮量 $150 \mathrm{~kg} \mathrm{hm}^{-2}$ 处理增 产 $7.9 \%$ ，产量之间并无显著差异，施氮 $150 \mathrm{~kg} \mathrm{hm}^{-2}$ 不仅百千克籽粒吸氮量较低, NAE 和 NUE 也比施氮 $225 \mathrm{~kg} \mathrm{hm}^{-2}$ 处理分别提高 $0.66 \mathrm{~kg} \mathrm{~kg}^{-1} 、 4.43 \mathrm{~kg} \mathrm{~kg}^{-1}$, 从 降低成本角度考虑, 施氮 $150 \mathrm{~kg} \mathrm{hm}^{-2}$ 既可以获得高 产，也使氮肥利用效率处在较高的水平。

3.2 水氮处理下土壤硝态氮含量及淋失情况

灌水与施氮也是影响土壤剖面氮素积累与淋溶 的关键因素。硝态氮在土壤剖面中的含量及其空间 分布是硝态氮淋失风险的重要指标，淋洗峰越深则 深层土壤硝态氮积累量越高 ${ }^{[32]}$ 。前人大量研究表明, 
施氮量增加, 土层中硝态氮残留量随之增加, 而随 着灌水量增加, 土壤中氮素会向下移动 ${ }^{[26,33-34]}$ 。土壤 剖面不同层次累积硝态氮随土层加深对后茬作物的 有效性显著降低, $75 \mathrm{~cm}$ 处已很难被作物利用, 淋溶 风险较高 ${ }^{[35]}$ 。因此, 本试验将 80 200 $\mathrm{cm}$ 土层的硝 态氮积累量定义为硝态氮淋失量。结果表明, W0 (不 灌水)处理下高施氮区表层土壤硝态氮含量显著高 于低施氮区, 硝态氮积累峰在 $60 \mathrm{~cm}$ 土层之上, 而 灌水处理深层土壤硝态氮含量远远高于表层土壤, 并且随着施氮量的增多, 深层土壤的硝态氮含量增 大, $\mathrm{W} 1$ 处理下硝态氮积累峰在土层 $160 \mathrm{~cm}$ 上下波 动, 而 W2 处理下的硝态氮积累峰已经下移到 200 $\mathrm{cm}$ 之下, 表明随着灌水增多, 硝态氮向土壤深层迁 移加剧。两季小麦收获后, 灌水处理下 80 200 cm 的硝态氮大量积累, 根据拟合方程 2017-2018 年 $y$ $=89.42+1.72 x+0.005 x^{2}, R^{2}=0.965 ; 2018-2019$ 年 $y=$ $92.14+1.056 x+0.009 x^{2}, R^{2}=0.981$, 说明施氮量越高 硝态氮在深层土壤中的累积量越大, 即硝态氮淋失 量越大。本试验中 $0 \sim 20 \mathrm{~cm}$ 土层硝态氮较其他研究 偏低, 一方面可能是作物吸收利用表层土壤硝态氮, 另一方面可能是硝态氮随雨水及灌溉向下迁移到深 层土壤中。根据产量效应与环境效应综合分析, 本试 验中越冬期灌水 $600 \mathrm{~m}^{3} \mathrm{hm}^{-2}$, 减量施氮 $50 \%$ 即施氮 $150 \mathrm{~kg} \mathrm{hm}^{-2}$, 可以在保证产量的基础上降低深层土 壤硝态氮含量, 也降低了硝态氮随灌水淋溶到深层 土壤的风险，避免了氮肥浪费。

\section{4 结论}

2017-2019 年试验小麦越冬期灌水 $600 \mathrm{~m}^{3} \mathrm{hm}^{-2}$ 就可以满足小麦生长需求获得高产。在此条件下, 氮肥利用效率均以施氮 $150 \mathrm{~kg} \mathrm{hm}^{-2}$ 处理更高, 并且 土壤硝态氮含量和硝态氮淋失量保持在一个相对较 低的水平。因此综合考虑不同水氮处理下冬小麦的 产量水平、水肥利用效率以及环境效应, 关中平原 节水灌溉农业生产在越冬期灌水 $600 \mathrm{~m}^{3} \mathrm{hm}^{-2}$, 减量 施氮 $50 \%$ 即施氮 $150 \mathrm{~kg} \mathrm{hm}^{-2}$ 条件下, 可获得较高的 籽粒产量, 提高氮肥利用率, 可以作为关中平原兼 顾作物产量与生态效益的节水减氮生产模式的参考 指标。

\section{References}

[1] 唐文雪, 马忠明, 王景才. 施氮量对旱地全膜双垄沟播玉米田 土壤硝态氮、产量和氮肥利用率的影响. 干旱地区农业研究, 2015, 33(6): 58-63.
Tang W X, Ma Z M, Wang J C. Effects of nitrogen rate on soil nitrate-N, yield and nitrogen use efficiency of double-ridge furrow sowing with full plastic film mulching for maize in dryland. Agric Res Arid Areas, 2015, 33(6): 58-63 (in Chinese with English abstract).

[2] 朱兆良. 农田中氮肥的损失与对策. 土壤与环境, 2000, (1): $1-6$.

Zhu Z L. Loss of fertilizer $\mathrm{N}$ from plant-soil system and the strategies and techniques for its reduction. Ecol Environ Sci, 2000, (1): 1-6 (in Chinese with English abstract).

[3] 巨晓棠, 谷保静. 氮素管理的指标. 土壤学报, 2017, 54: 281-296.

Ju X T, Gu B J. Indexes of nitrogen management. Acta Pedol Sin, 2017, 54: 281-296 (in Chinese with English abstract).

[4] 常艳丽, 刘俊梅, 李玉会, 孙本华, 张树兰, 杨学云. 陕西关 中平原小麦/玉米轮作体系施肥现状调查与评价. 西北农林科 技大学学报(自然科学版), 2014, 42(8): 51-61.

Chang Y L, Liu J M, Li Y H, Sun B H, Zhang S L, Yang X Y. Investigation and evaluation of fertilization under winter wheat and summer maize rotation system in Guanzhong plain, Shaanxi province. $J$ Northwest A\&F Univ (Nat Sci Edn), 2014, 42(8): 51-61 (in Chinese with English abstract).

[5] 张明, 同延安, 郭俊炜, 张树兰, 郭盼. 陕西关中小麦/玉米轮 作区氮肥用量及施氮现状评估. 西北农林科技大学学报(自然 科学版), 2011, 39(4): 152-158.

Zhang M, Tong Y A, Guo J W, Zhang S L, Guo P. Determination of reasonable nitrogen use and evaluation of application status in wheat/maize rotation system in Guangzhong area of Shaanxi province. J Northwest A\&F Univ (Nat Sci Edn), 2011, 39(4): 152-158 (in Chinese with English abstract).

[6] 同延安, Ove E, 张树兰, 梁东丽. 陕西省氮肥过量施用现状评 价. 中国农业科学, 2004, 37: 1239-1244.

Tong Y A, Ove E, Zhang S L, Liang D L. Evaluation of over application of nitrogen fertilizer in China's, Shaanxi province. Sci Agric Sin, 2004, 37: 1239-1244 (in Chinese with English abstract).

[7] 冯波, 孔令安, 张宾, 司纪升, 李升东, 王法宏. 施氮量对垄 作小麦氮肥利用率和土壤硝态氮含量的影响. 作物学报, 2012, 38: 1107-1114.

Feng B, Kong L A, Zhang B, Si J S, Li S D, Wang F H. Effect of nitrogen application level on nitrogen use efficiency in wheat and soil nitrate-N content under bed planting condition. Acta Agron Sin, 2012, 38: 1107-1114 (in Chinese with English abstract).

[8] 郭天财, 宋晓, 冯伟, 马冬云, 谢迎新, 王永华. 高产麦田氮 素利用、氮平衡及适宜施氮量. 作物学报, 2008, 34: 886-892. Guo T C, Song X, Feng W, Ma D Y, Xie Y X, Wang Y H. Utilization and balance of nitrogen and proper application amount of nitrogen fertilizer in winter wheat in high-yielding regions. Acta Agron Sin, 2008, 34: 886-892 (in Chinese with English abstract).

[9] 李正鹏, 宋明丹, 冯浩. 不同降水年型水氮运筹对冬小麦耗水 和产量的影响. 农业工程学报, 2018, 34(18): 160-167.

Li Z P, Song M D, Feng H. Effects of irrigation and nitrogen application on water consumption and yield of winter wheat in different precipitation years. Trans CSAE, 2018, 34(18): 160-167 (in Chinese with English abstract). 
[10] 金修宽, 马茂亭, 赵同科, 安志装, 姜玲玲. 测墒补灌和施氮 对冬小麦产量及水分、氮素利用效率的影响. 中国农业科学, 2018, 51: 1334-1344.

Jin X K, Ma M T, Zhao T K, An Z Z, Jiang L L. Effects of nitrogen application on yield, water and nitrogen use efficiency of winter wheat under supplemental irrigation based on measured soil moisture content. Sci Agric Sin, 2018, 51: 1334-1344 (in Chinese with English abstract).

[11] 张勇. 从陕西水资源状况看节水灌溉. 干旱地区农业研究, 2002, 20(3): 60-62.

Zhang Y. Water resources and water-saving irrigation in Shaanxi province. Agric Res Arid Areas, 2002, 20(3): 60-62 (in Chinese with English abstract).

[12] 潘家荣, 巨晓棠, 刘学军, 陈新平, 张福锁, 毛达如. 水氮优 化条件下在华北平原冬小麦/夏玉米轮作中化肥氮的去向. 核 农学报, 2009, 23: 334-340.

Pan J R, Ju X T, Liu X J, Chen X P, Zhang F S, Mao D R. Fate of fertilizer nitrogen for winter wheat/summer maize rotation in North China Plain under optimization of irrigation and fertilization. J Nucl Agric Sci, 2009, 23: 334-340 (in Chinese with English abstract).

[13] 张经廷, 陈青云, 吕丽华, 申海平, 贾秀领, 梁双波. 冬小麦夏玉米轮作产量与氮素利用最佳水氮配置. 植物营养与肥料 学报, 2016, 22: 886-896.

Zhang J T, Chen Q Y, Lyu L H, Shen H P, Jia X L, Liang S B. Optimum combination of irrigation and nitrogen for high yield and nitrogen use efficiency in winter wheat and summer maize rotation system. J Plant Nutr Fert Sci, 2016, 22: 886-896 (in Chinese with English abstract).

[14] 张凤翔, 周明耀, 徐华平, 郭凯泉. 水肥耦合对冬小麦生长和 产量的影响. 水利与建筑工程学报, 2005, 3(2): 22-24.

Zhang F X, Zhou M Y, Xu H P, Guo K Q. Effects of water and fertilizer coupling on growing and yield of winter wheat. $J$ Water Resour Architect Engin, 2005, 3(2): 22-24 (in Chinese with English abstract).

[15] 周昌明, 李援农, 蒋耿民, 李莎, 白麟, 吕静. 不同水氮处理 对冬小麦生长及土壤硝态氮含量的影响. 西北农林科技大学 学报(自然科学版), 2013, 41(5): 52-58.

Zhou C M, Li Y N, Jiang G M, Li S, Bai L, Lyu J. Effect of different water and nitrogen treatments on growth of winter wheat and soil nitrate content. $J$ Northwest $A \& F$ University (Nat Sci Edn), 2013, 41(5): 52-58 (in Chinese with English abstract).

[16] 张秀, 朱文美, 代兴龙, 初金鹏, 钤太峰, 贺明荣. 施氮量对 强筋小麦产量、氮素利用率和品质的影响. 麦类作物学报, 2018, 38: 963-969.

Zhang X, Zhu W M, Dai X L, Chu J P, Qian T F, He M R. Effect of nitrogen application rate on grain yield, nitrogen use efficiency and grain quality of strong gluten wheat. J Triticeae Crops, 2018, 38: 963-969 (in Chinese with English abstract).

[17] 王成雨, 石玉华, 井跃博. 持续减量施氮对冬小麦土壤硝态氮 含量和氮肥利用效率的影响。中国农业气象, 2013，34: 642-647.

Wang C Y, Shi Y H, Jing Y B. Effects of decreasing nitrogen inputs on nitrate-nitrogen in soil and nitrogen fertilizer use efficiency. Chin J Agrometeorol, 2013, 34: 642-647 (in Chinese with English abstract).
[18] 刘学军, 巨晓棠, 张福锁. 减量施氮对冬小麦-夏玉米种植体 系中氮利用与平衡的影响. 应用生态学报, 2004, 15: 458-462.

Liu X J, Ju X T, Zhang F S. Effect of reduced N application on N utilization and balance in winter wheat- summer maize cropping system. Chin J Appl Ecol, 2004, 15(3): 458-462 (in Chinese with English abstract).

[19] 杨新泉, 冯锋, 宋长青, 冷疏影. 主要农田生态系统氮素行为 与氮肥高效利用研究. 植物营养与肥料学报, 2003, 9: 373-376. Yang X Q, Feng F, Song C Q, Leng S Y. Fate and efficient use of nitrogen fertilizer in main agroecosystems. Plant Nutr Fert Sci, 2003, 9: 373-376 (in Chinese with English abstract).

[20] 吕丽华, 董志强, 张经廷, 张丽华, 梁双波, 贾秀领, 姚海坡. 水氮对冬小麦-夏玉米产量及氮利用效应研究. 中国农业科学, 2014, 47: 3839-3849.

Lyu L H, Dong Z Q, Zhang J T, Zhang L H, Liang S B, Jia X L, Yao H P. Effect of water and nitrogen on yield and nitrogen utilization of winter wheat and summer maize. Sci Agric Sin, 2014, 47: 3839-3849 (in Chinese with English abstract).

[21] 张玉铭, 张佳宝, 胡春胜, 赵炳梓, 朱安宁, 张立周, 宋利娜. 水肥耦合对华北高产农区小麦-玉米产量和土壤硝态氮淋失风 险的影响. 中国生态农业学报, 2011, 19: 532-539.

Zhang Y M, Zhang J B, Hu C S, Zhao B Z, Zhu A N, Zhang L Z, Song L N. Effect of fertilization and irrigation on wheat-maize yield and soil nitrate nitrogen leaching in high agricultural yield region in North China Plain. Chin J Eco-Agric, 2011, 19: 532-539 (in Chinese with English abstract).

[22] 王小燕, 褚鹏飞, 于振文. 水氮互作对小麦土壤硝态氮运移及 水、氮利用效率的影响. 植物营养与肥料学报, 2009,15 : 992-1002.

Wang X Y, Chu P F, Yu Z W. Effects of irrigation and nitrogen on soil $\mathrm{NO}_{3}-\mathrm{N}$ transport, nitrogen use efficiency and water use efficiency in wheat. Plant Nutr Fert Sci, 2009, 15: 992-1002 (in Chinese with English abstract).

[23] 张玉铭, 张佳宝, 胡春胜, 李晓欣, 朱安宁. 华北太行山前平 原农田土壤水分动态与氮素的淋溶损失. 土壤学报, 2006, 43: $17-25$.

Zhang Y M, Zhang J B, Hu C S, Li X X, Zhu A N. Nitrate leaching in wheat-maize rotation field in the North China Plain. Acta Pedol Sin, 2006, 43: 17-25 (in Chinese with English abstract).

[24] 茹淑华, 张国印, 孙世友, 耿暖, 王凌. 不同施氮量对华北平 原作物产量及土体硝态氮分布和累积的影响. 华北农学报, 2012, 27(6): 172-177.

Ru S H, Zhang G Y, Sun S Y, Geng N, Wang L. Effect of different nitrogen application rate on soil nitrate nitrogen distribution, accumulation and crop yields of Northern China Plain. Acta Agric Boreali-Sin, 2012, 27(6): 172-177 (in Chinese with English abstract).

[25] 郑成岩, 于振文, 王西芝, 武同华. 灌水量和时期对高产小麦 氮素积累、分配和转运及土壤硝态氮含量的影响. 植物营养与 肥料学报, 2009, 15: 1324-1332.

Zheng C Y, Yu Z W, Wang X Z, Wu T H. Effects of irrigation amount and stage on nitrogen accumulation, distribution, translocation and soil $\mathrm{NO}_{3}{ }^{-}-\mathrm{N}$ content in high-yield wheat. Plant Nutr Fert Sci, 2009, 15: 1324-1332 (in Chinese with English abstract).

[26] 栗丽, 洪坚平, 王宏庭, 谢英荷. 水氮互作对冬小麦氮素吸收 分配及土壤硝态氮积累的影响. 水土保持学报, 2013, 27(3): 
138-142.

Li L, Hong J P, Wang H T, Xie Y H. Effects of nitrogen interaction on nitrogen uptake and distribution in winter wheat and nitrate accumulation in soil. J Soil Water Conserv, 2013, 27(3): 138-142 (in Chinese with English abstract).

[27] 薛崧, 吴小平, 冯彩平, 张倩. 不同氮素水平对旱地小麦叶片 叶绿素和糖含量的影响及其与产量的关系. 干旱地区农业研 究, 1997, 15(1): 82-87.

Xue S, Wu X P, Feng C P, Zhang Q. Effects of N fertilizer on the amount of chlorophyll and carbohydrate in dryland wheat leaf and the relationship between $\mathrm{N}$ fertilizer and wheat yield. Agric Res Arid Areas, 1997, 15(1): 82-87 (in Chinese with English abstract).

[28] 王祖力, 肖海峰. 化肥施用对粮食产量增长的作用分析. 农业 经济问题, 2008, (8): 65-68.

Wang Z L, Xiao H F. Analysis on the effect of fertilizer application on grain yield growth. Issu Agric Econ, 2008, (8): 65-68 (in Chinese).

[29] Dobermann A, Cassman K G. Plant nutrient management for enhanced productivity in intensive grain production systems of the United States and Asia. Plant Soil, 2002, 247: 153-175.

[30] 戴健, 王朝辉, 李强, 李孟华, 李富翠. 氮肥用量对旱地冬小 麦产量及夏闲期土壤硝态氮变化的影响. 土壤学报, 2013, 50: 956-965.

Dai J, Wang Z H, Li Q, Li M H, Li F C. Effects of nitrogen application rate on winter wheat yield and soil nitrate nitrogen during summer fallow season on dryland. Acta Pedol Sin, 2013, 50: 956-965 (in Chinese with English abstract).

[31] 徐凤娇, 赵广才, 田奇卓, 常旭虹, 杨玉双, 王德梅, 刘金金. 施 氮量对不同品质类型小麦产量和加工品质的影响. 植物营养 与肥料学报, 2012, 18: 300-306.

Xu F J, Zhao G C, Tian Q Z, Chang X H, Yang Y S, Wang D M,
Liu X. Effects of nitrogen fertilization on grain yield and processing quality of different wheat genotypes. Plant Nutr Fert Sci, 2012, 18: 300-306 (in Chinese with English abstract).

[32] 张云贵, 刘宏斌, 李志宏, 林葆, 张夫道. 长期施肥条件下华 北平原农田硝态氮淋失风险的研究. 植物营养与肥料学报, 2005, 11: 711-716.

Zhang Y G, Liu H B, Li Z H, Lin B, Zhang F D. Study of nitrate leaching potential from agricultural land in Northern China under long-term fertilization conditions. Plant Nutr Fert Sci, 2005, 11: 711-716 (in Chinese with English abstract).

[33] 徐明杰, 董娴娴, 刘会玲, 张丽娟, 巨晓棠. 不同管理方式对 小麦氮素吸收、分配及去向的影响. 植物营养与肥料学报, 2014, 20: 1084-1093.

Xu M J, Dong X X, Liu H L, Zhang L J, Ju X T. Effects of different management patterns on uptake, distribution and fate of nitrogen in wheat. J Plant Nutr Fert Sci, 2014, 20: 1084-1093 (in Chinese with English abstract).

[34] 陈金, 唐玉海, 尹燕枰, 庞党伟, 崔正勇, 郑孟静, 彭佃亮, 杨 卫兵, 杨东清, 李艳霞, 王振林, 李勇. 秸秆还田条件下适量 施氮对冬小麦氮素利用及产量的影响. 作物学报, 2015, 41: 160-167.

Chen J, Tang Y H, Yin Y P, Pang D W, Cui Z Y, Zheng M J, Peng D L, Yang W B, Yang D Q, Li Y X, Wang Z L, Li Y. Effects of straw returning plus nitrogen fertilizer on nitrogen utilization and grain yield in winter wheat. Acta Agron Sin, 41: 160-167 (in Chinese with English abstract).

[35] 张丽娟, 巨晓棠, 张福锁, 彭正萍. 土壤剖面不同层次标记硝 态氮的运移及其后效. 中国农业科学, 2007, 40: 1964-1972.

Zhang L J, Ju X T, Zhang F S, Peng Z P. Movement and residual effect of labeled nitrate-N in different soil layers. Sci Agric Sin, 2007, 40: 1964-1972 (in Chinese with English abstract). 